\title{
Anaphor Binding: What French Inanimate Anaphors Show
}

\section{Citation}

Charnavel, Isabelle, and Dominique Sportiche. 2016. "Anaphor Binding: What French Inanimate Anaphors Show.” Linguistic Inquiry 47 (1) (January): 35-87. doi:10.1162/ling_a_00204.

\section{Published Version}

10.1162/LING_a_00204

\section{Permanent link}

http://nrs.harvard.edu/urn-3:HUL.InstRepos:25506701

\section{Terms of Use}

This article was downloaded from Harvard University's DASH repository, and is made available under the terms and conditions applicable to Open Access Policy Articles, as set forth at http:// nrs.harvard.edu/urn-3:HUL.InstRepos:dash.current.terms-of-use\#OAP

\section{Share Your Story}

The Harvard community has made this article openly available.

Please share how this access benefits you. Submit a story.

Accessibility 


\title{
Anaphor Binding Domains in French
}

\author{
Isabelle Charnavel \\ Harvard University
}

\author{
Dominique Sportiche \\ UCLA
}

\section{Introduction}

For twenty years or so, two influential but superficially incompatible versions of condition A (CA) of the Binding Theory (BT) have coexisted: Chomsky's 1986 version which we call the classical condition A, and versions of predicate based binding theories of Condition A (PB CA) defended in Pollard and Sag (1992) or Reinhart and Reuland (1993) modified in various ways since (Pollard, 2005, Reuland, 2011). These two approaches make substantially different predictions regarding the distribution of anaphors.

Given the central role played by binding theory in syntactic and semantic theories and their interface, it seems to us crucial to determine what exactly the correct generalizations are regarding the distribution of anaphors that theories need to account for.

In order to attempt to establish accurate formulation of such generalizations regarding the distribution of anaphors, we study the behavior of (some) anaphors in French, the only language we seriously discuss. As far as French is concerned, we conclude that the classical approach is correct, although over empirical domains, that we will delineate, different from what has been argued for by (most of) its proponents.

In a nutshell, we conclude that for the core case of Condition A, Chomsky's 1986 descriptive generalization (anaphors must be bound within the smallest complete functional complex containing it and a possible binder) is basically correct, with one amendment: a tensed TP boundary is opaque to the search for antecedent.

Given these descriptive generalizations, we argue that the locality imposed on anaphor/antecedent relations by the core case of Condition A should be reduced to Phase theory and we will outline how this could be done. More precisely, we will argue that condition $\mathrm{A}$ is a reflex of the requirement that an anaphor contained in some spell out domain be interpreted in that domain.

The article is organized as follows.

In section 1, we discuss what binding theory ought to account for. In particular we discuss why it is necessary, as is now well known, to separate plain anaphors subject to Condition A, from exempt anaphors subject to different restrictions, and how this can be done in principle by studying the difference (roughly) between inanimate anaphors, which we argue must be plain, and non-inanimate anaphors, which do not have to be.

In sections 2, and 3, following up the outlines of this strategy to distinguish plain from exempt anaphors introduced in section 1 , we justify it by studying some French anaphors, illustrating on the way central difficulties of predicate based approaches: we more systematically discuss the distribution of the anaphors son (propre) in section 2, and elle-même in section 3, which leads to several descriptive generalizations, essentially vindicating the classical Condition A. In section 4, we corroborate our conclusions by examining inclusive reference cases. In section 5, we discuss a limited number of cases left unexplained by our proposals in which French anaphors are excluded. We follow previous work in concluding these exclusions are due to a different system involving competition between alternative realizations of pronouns. 
In section 6, we will discuss how the locality imposed by condition A could be reduced to Phase theory.

\section{A central problem: Distinguishing Plain from Exempt Anaphors}

Starting from (Standard American) English, the contrast between the following two examples:

(1) a. The moon spins on itself

b. * The moon influences people sensitive to itself

shows that an expression such as itself tolerates a local antecedent in (1a) but not a more distant antecedent as in (1b). Call such distance sensitive expressions anaphors. In a given language the binding theory seeks to answer the following kind of questions, with hopes of finding crosslinguistically valid answers:

1. Which expressions are anaphors?

2. What makes an expression anaphoric?

3. What are the descriptive generalizations concerning the distribution of anaphors?

4. Where do these generalizations come from: how should they be derived from theoretical primitives?

We will not attempt here to answer all these questions (for French). We will try to identify a subset of anaphors in French, and address question 3 (in sections 2 and 3), and question 4 in part (in section 6). ${ }^{1}$

Clearly, answering the first question, at least partially, is a prerequisite to answering the others: if we do not know at all what the anaphors are, it is difficult to answer questions about them. The difficulty of answering the first question is illustrated by the English paradigm below:

(2) a. John likes himself.

b. * John says that Mary likes himself.

c. John says that Mary likes everyone but himself.

Himself seems to be the kind of expression needing a local antecedent as the contrast between (2a) and (2b) shows, yet (2c) is typically judged fine even though the very same element himself is involved, and by reasonable measures (depth of embedding), is further away from its antecedent than in (2b).

The classical BT does not address sentences such as (2c). One of the merits of PB theories is precisely that they do: they distinguish cases of plain anaphors as in (2b) from cases of exempt anaphors as in (2c). They take it that plain anaphors are subject to locality restrictions such as condition A (the (2a/b) contrast), while exempt anaphors are not distance sensitive, at

\footnotetext{
${ }^{1}$ One common answer to question 2 is that anaphors are referentially deficient which strikes us as nearly tautological. We would take as explanatory a compositional theory of what makes an expression such as e.g. himself an anaphor based on the properties of its part (a pronoun and self). Neither will we address such questions as “what is a binding relation” discussed for example in Rooryck and van den Wyngaerd (2011).
} 
least not in the same way, the (2b/c) contrast. This means the four questions above really are eight questions, four for plain anaphors and of course four for exempt anaphors.

Very roughly, all theories agree that plain anaphors are expressions that must be bound within some local domain by a c-commanding antecedent (however this is enforced).

It would seem that the first question that needs to be answered is how to precisely and independently separate plain anaphors from exempt anaphors especially when they are homophonous as e.g. English $X$-self, or Chinese ziji (cf. Huang and Liu, 2001). Yet this is not how the PB BTs proceed. What they take to be exempt is a consequence of theoretical assumptions about how Condition A should apply (e.g. be predicate based). They do post hoc try to correlate being exempt with other properties, but we believe the claimed correlations fail (we will discuss this in section 4).

We now argue we should proceed differently based on the substantial amount of (descriptive) work done since these early PB theories were proposed. In particular, some crosslinguistic generalizations hold widely of exempt anaphors: ${ }^{2}$ while exactly how exempt anaphora functions is not known - there are many perhaps not incompatible proposals regarding what is involved e.g. logophoricity, perspective, point of view, empathy $-{ }^{3}$ there is a wide and robust crosslinguistic generalization, namely that (the referent of) the antecedent of an exempt anaphor must (in principle) be capable of speech, thought, of holding a perspective, of having a point of view or of being an empathic target. While there are circumscribed exceptions (which interestingly appear to be culture sensitive regarding sentience) this means that such referents must be (live) persons. ${ }^{4}$

This simple descriptive generalization provides an angle to directly investigate what is not covered under exempt anaphora, namely looking at the behavior of inanimate anaphors. This is what we do in the next three sections (for French), justifying the idea that looking at inanimate anaphors tells us the scope of condition A and showing some shortcomings of $\mathrm{PB}$ approaches. We will do this with two elements which we show are anaphoric, elle-même (lit. her-same, her-even) and related expressions (lui-même, eux-mêmes / him-same, them-same, etc...) and son (his) as part of the expression son propre (his-own) when it is understood as inducing focus alternatives on the possessor son (e.g. her own and not his own).

And we will show that (French) inanimate anaphors are never exempt. At the same time, we show that PB BT's are both too strong and too weak to handle the distribution of such anaphors.

\subsection{Separating plain anaphors from exempt anaphors: the coargument view}

We begin by briefly introducing the main tenets of PB theories' treatments of anaphors.

\footnotetext{
${ }^{2}$ As first approximation, we take to be instances of exempt anaphors these expressions that can, like plain anaphors, be bound locally (unlike pronouns), and long distance. This will be refined in the course of the discussion.

${ }^{3}$ See e.g. Anand, 2006; Huang \& Liu, 2001; Kuno, 2004; Oshima, 2006; Schlenker, 2003; Sells, 1987; ZribiHertz, 1989.

${ }^{4}$ We will from now on code the relevant distinction as animate vs. inanimate but it should be kept in mind that this is too rough a characterization as seemingly non animate terms can be used as proxy for people (e.g. the parliament, Washington, Japan) that is as referents capable of thought or point of view, etc..
} 


\subsubsection{The basics}

As mentioned, PB BT's have the virtue of systematically taking into account a needed distinction between plain and exempt anaphors. Disregarding some details, ${ }^{5}$ both main predicate based theories - Pollard and Sag (1992) and Reinhart and Reuland (1993) - amount to assuming that an anaphor must be bound by a syntactic coargument if there is one, otherwise it is exempt from binding requirements. This accounts for contrasts found in (3), due to Zribi-Hertz (1989), that are not predicted by the classical theory:

(3) a. * It angered him that $_{\mathrm{i}}$ she liked himself $\mathrm{i}_{\mathrm{i}}$

b. It angered himi that she liked a man like himself $f_{\mathrm{i}}$.

Chomsky (1986) wrongly predicts both sentences to be ungrammatical: the binding domain of the reflexive is the embedded infinitive, i.e. she liked himself/a man like himself, and the intended antecedent for himself, i.e. him, is situated outside of it. However, these two sentences crucially differ if we adopt the coargument view: in (3a), himself has a coargument, i.e. she, but is not bound by it, therefore the sentence is correctly predicted to be ungrammatical; in (3b), himself does not have any coargument since it is not the complement of liked but only part of it, and is thus predicted to be exempt from Condition A, which correctly derives the acceptability of the sentence. ${ }^{6}$

In sum, predicate-based theories like Pollard and Sag (1992)'s and Reinhart and Reuland (1993)'s solve the empirical problems faced by the classical binding theory by invoking exempt positions, i.e. positions in which reflexives do not need to be bound.

\subsubsection{Exempt positions}

According to PB theories, there are three main cases of exempt positions. First, reflexives are exempt when they are the single argument of a predicate, in particular in DPs or PPs like the following: ${ }^{7}$

(4) Lucie $_{i}$ saw a picture of herself ${ }_{i}$.

(5) Max $_{\mathrm{i}}$ rolled the carpet over himself $\mathrm{f}_{\mathrm{i}}$

In (4), the anaphor herself is the only argument of picture and is thus exempt from condition A; similarly in (5), himself is the single argument of the preposition over. ${ }^{8}$

Second, reflexives are exempt when they are part of an argument as in e.g. coordination as illustrated by (6):

(6) Max $_{\mathrm{i}}$ boasted that the queen invited Lucie and himself $f_{\mathrm{i}}$ for a drink.

\footnotetext{
${ }^{5}$ One difference between Pollard and Sag (1992) and Reinhart and Reuland (1993) is inconsequential here: according to the latter, one of its coargument must be a subject for the reflexive to be non-exempt. For Reuland (2011), if the predicate the anaphor is an argument of does not have an event argument, the anaphor is exempt. ${ }^{6}$ This relies on the assumption that the preposition like does not form a predicate with subject, which is far from clear. The natural assumption is that like has a subject and man like himself is a relative. Reuland (2011) probably does not have this problem, see fn 5 .

${ }^{7}$ Although once again, it is unclear why a preposition like over, a two place predicate, does not have a (silent) subject. And once again, Reuland (2011) probably does not have this problem, see fn 5.

${ }^{8}$ Technically speaking in Reinhart and Reuland (1993) (resp. Reuland (2011)), the exemption comes from the fact that the predicates picture and over lack a subject (resp. an event argument).
} 
Here, the anaphor is embedded in an argument: the complement of invite is Lucie and himself. As himself lacks a coargument, it is exempt from condition A.

The third case where reflexives are exempt according to Reinhart and Reuland (1993) corresponds to focus anaphors: they assume that condition A applies at LF and the focused expression undergoes movement at LF; in examples like the following, the anaphor is no longer in an argument position as shown in the representation in (7b), and is therefore exempt:

(7) a. This letter was addressed only to myself $\mathrm{i}_{\mathrm{i}}$.

b. myself $\mathrm{i}_{\mathrm{i}}$ (This letter was addressed only to $\mathrm{e}_{\mathrm{i}}$ ).

In sum, setting focus aside, positions subdivide in two disjoint subsets according to the coargument view: coargumental positions and non-coargumental positions. In the latter cases, reflexives are exempt from condition A.

\subsection{Separating plain anaphors from exempt anaphors: the roadmap}

The coargument view betters the classical view in accounting for examples involving exempt anaphora. In the next sections, we discuss what we call "possessor son propre" and elle-même. We will show that each can be either a plain or an exempt anaphor. We will also show that they need not be coindexed with a coargument in (what PB approaches characterize as) non-exempt positions: the coargument view is thus too strong. And we will also show that when they are plain anaphors (as e.g. when they are inanimate) they obey locality constraints even in what PB theories characterize as exempt positions: such theories are thus too weak.

We conclude that it is therefore not the type of position (coargumental vs. non-coargumental) that is crucial to the plain/exempt dichotomy, but the type of antecedent (roughly animate vs. inanimate, see fn 4); in other terms, the necessary theory of exemption should not be based on the absence of coargumenthood, but on the interpretation of the antecedent of the anaphor. Probing the data configuration will lead to the conclusion that the classical theory can be maintained for non-exempt anaphors, but needs to be complemented to incorporate the possibility of exemption. In sum, because a criterion independent from locality, namely inanimacy, can be provided to distinguish between exempt and non-exempt anaphors, we conclude that (a version of) the classical condition A regulates the distribution of plain anaphors (in French).

\section{Arguments from son propre}

We begin by discussing what we call possessor son propre (her own), that is the referential properties of the genitive son (his/her/its) when it occurs in conjunction with the adjective propre (lit. specific to) and induces focus alternatives to the possessor. Indeed, the expression son propre can yield different interpretations e.g. possessor son propre, possessum son propre, etc.. ${ }^{9}$ Only the former exhibits a correlation between animacy and binding locality. To guarantee this reading, e.g. son propre roughly meaning 'her own and not someone else's', the examples will have to be read in contexts that make alternatives to the possessor salient. In most cases, explicit alternatives to the possessor will occur in the sentence itself to make this possessor reading even more salient.

\footnotetext{
${ }^{9}$ A full discussion can be found in Charnavel (2012).
} 


\subsection{Why the coargument view is too weak}

First, data involving possessor son propre demonstrate that the coargument view is too weak: son propre is subject to syntactic restrictions of locality even when it is supposed to be exempt.

We observe the following contrast:

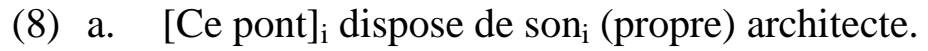

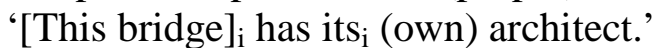

b. [Ce pont $]_{\mathrm{i}}$ a l'air très fragile. Son ${ }_{\mathrm{i}}\left({ }^{*} \text { propre }\right)^{10}$ architecte a reçu moins de moyens que les autres architectes de la région.

'[This bridge $]_{\mathrm{i}}$ looks very fragile. Its $_{\mathrm{i}}\left({ }^{*}\right.$ own) architect got less means than the other architects of the area.'

c. [Cet enfant $]_{\mathrm{i}}$ a l'air très perturbé. Sa $\mathrm{a}_{\mathrm{i}}$ (propre) mère passe moins de temps à la maison que les autres mères de la classe.

'[This child $]_{\mathrm{i}}$ looks very disturbed. His $\mathrm{i}_{\mathrm{i}}$ (own) mother spends less time at home than the other mothers of the children in the class.'

(8) illustrates that inanimacy and locality of the antecedent correlate, i.e. if the antecedent is inanimate, it must locally bind son propre: thus in (8a), inanimate ce pont ('this bridge') locally binds son propre and the sentence is grammatical, while in (8b), ce pont and son propre are not clausemates, which makes propre unacceptable; however in (8c), the antecedent cet enfant ('this child') is animate, and the sentence is fine even if it is not in the same clause as son propre.

The coargument view does not predict this configuration of data.

For Pollard and Sag (1992) or Reinhart and Reuland (1993), son propre is the single argument of the nominal predicate architecte ('architect'), so that there is no coargument it could be coindexed with, which exempts it from condition A. For Reuland (2011: 254), condition A only applies to arguments of predicates denoting events, where verbs are assumed to have an e-role (event role) whereas N's and P's are not, so such cases are not relevant.

If exemption is defined positionally, we face the following dilemma: if son propre is exempt, all three sentences should be fine, but they are not.

if son propre is not exempt, the last two sentences should be equally bad but they are not. ${ }^{11}$

Assuming that son propre is exempt in (8), it should be acceptable whatever the position of the antecedent is according to the coargument view since condition A does not apply: in particular, clausemateness should not matter. But (8) suggests it does, since inanimate son propre is grammatical when the antecedent is clausemate as in (8a), but not when it is not as in (8b).

In other terms, condition A of the coargument view is too weak to predict the contrast between (8a) and (8b). This is not a direct argument against the coargument view since in principle, we could simply add another condition to account for the contrast. In particular,

\footnotetext{
${ }^{10}$ As is standard, the star $(*)$ is used contrastively: it does not necessarily mean that the sentence is completely unacceptable but indicates that the sentence is significantly more degraded than the corresponding sentence without a star. The data has two sources, elicitation judgment and an online judgment task questionnaire statistically analyzed presented in Charnavel (2012, chapter 1, appendix).

${ }^{11}$ This is the problem faced by Reinhart and Reuland (1993)'s theory: son propre is not predicted to be exempt in this case (since it is analyzed as the subject of the predicate architecte ('architect') so this predicate both has a subject and a reflexive argument).
} 
advocates of the coargument view themselves (Pollard and Sag 1992: 271-279; Reinhart and Reuland 1993: 673) suggest that discourse constraints like perspective or accessibility may regulate the use of exempt anaphors. Thus at first glance, it seems possible to maintain the coargument view if we suppose that the contrast between (8b) and (8c) is due to additional constraints related to discourse: both contain exempt son propre so that condition A does not apply, but the difference in animacy accounts for the difference of grammaticality because of other kinds of constraints.

Note first that if animacy is a relevant factor, we should, by Occam's razor, determine whether it is the only relevant factor (we end up concluding that it is).

Furthermore, if constraints on the antecedent accounted for the $(8 b) /(8 c)$ contrast, the contrast $(8 a) /(8 b)$ would remain unexpected. Indeed both (8a) and (8b) exhibit inanimate son propre, take a subject with the same content as antecedent which occurs in configurations licitly anteceding exempt anaphors. But inanimate son propre is only acceptable when the antecedent occurs in the same clause as in (8a) (and in fact, as we will amply demonstrate below, requires a local c-commanding antecedent): inanimacy of an anaphor correlates with locality. ${ }^{12}$ It can therefore be concluded that the coargument view does not draw the right dividing line between exempt and non-exempt anaphors: ${ }^{13}$ the division should not be based on coargumenthood, but on interpretive properties of the antecedent related to animacy; and condition A is not based on coargumenthood but on some notion of syntactic locality as we will see. This will allow us to predict that son propre in (8a) and (8b) is not exempt because it is inanimate and thus subject to condition A, while son propre in (8c) can be exempt because it is animate.

\subsection{Assessing c-command}

The first defining criterion for locality is c-command: as we now show, inanimate son propre must be c-commanded by its antecedent. This is illustrated by the following contrast:

(9) a. [Ce problème $]_{\mathrm{i}}$ inclut sa $\mathrm{a}_{\mathrm{i}}$ (propre) solution et celle du problème précédent. '[This problem $]_{i}$ includes its

b. Les annexes de [ce problème $]_{\mathrm{i}}$ incluent $\mathrm{sa}_{\mathrm{i}}\left({ }^{*}\right.$ propre) solution et celle du problème précédent.

'The appendices of [this problem $]_{\mathrm{i}}$ include its ${ }_{\mathrm{i}}\left({ }^{*}\right.$ own $)$ solution and that of the previous problem.'

In (9a), the inanimate antecedent ce problème ('this problem') c-commands sa propre and the sentence is fully acceptable, as opposed to (9b) where the antecedent does not c-command sa propre.

The following example makes clear that the relevant notion is indeed c-command and not subject orientation: like (9), it exhibits a contrast with respect to c-command between (10a) and (10b), but in this case, the antecedent appears in an object position instead of a subject position.

(10)a. J'ai lavé [la fontaine $]_{i}$ avec sa ${ }_{i}$ (propre) eau par souci d'économie.

\footnotetext{
12 This is more generally shown by the questionnaire referred to in fn 9 .

${ }^{13}$ There is a third option, namely claiming that there are two kinds of exemptions, one, standard, applying only to animate anaphors, and another, applying to all anaphors in non coargumental positions and still requiring a local antecedent. Such a view would be the weakest option and as such ad hoc. See also section 4.4 for further discussion.
} 
'I washed [the fountain $]_{i}$ with its ${ }_{i}$ (own) water out of concern for saving water.'

b. J'ai lavé les rebords de [la fontaine $]_{i}$ avec $\mathrm{sa}_{\mathrm{i}}$ (*propre) eau par souci d'économie. 'I washed the edges of [the fountain] with its ${ }_{\mathrm{i}}\left({ }^{*} \mathrm{own}\right)$ water out of concern for saving water.'

Here sa propre is c-commanded by its antecedent la fontaine ('the fountain') occurring in the object position in (10a), but it is not in (10b), and the absence of c-command correlates with the ungrammaticality of son propre.

Note also that inanimate son propre is not subject to intervention effects, whether with animates or inanimates:

(11) a. [Ce problème $]_{\mathrm{i}}$ amène les étudiants/l'étudiant à sa ${ }_{\mathrm{i}}$ (propre) solution et à celle du problème précédent.

'[This problem $]_{i}$ leads the students/the student to its $s_{i}$ (own) solution and that of the previous problem.'

b. [Le fleuve $]_{i}$ emporte les déchets/tout déchet vers $\mathrm{sa}_{\mathrm{i}}$ (propre) embouchure. '[The river $]_{i}$ sweeps waste/every waste away towards its ${ }_{i}($ own) mouth.'

In (11a), sa propre is anteceded by the inanimate ce problème ('this problem') even though the animate les étudiants ('the students') intervenes. Similarly in (11b), sa propre is bound by le fleuve ('the river') even if les déchets (pl. 'waste') is an intermediate c-commander. This is so whether the intervener agrees (in number) with sa propre or not as indicated in each example. These sentences show that inanimate son propre does not need to be bound by the closest binder, nor does it give priority to animate antecedents over inanimate ones. This will matter for examples showing intervention effects with subjects in section 2.3.

\subsection{Calibrating binding domains}

The antecedent must not only c-command inanimate son propre, it must also occur in the local domain of inanimate son propre, which can be characterized as the smallest XP with an intervening subject containing it, as will be shown. This generalization is based on sentences involving TPs, small clauses and DPs.

First, the status of son propre differs in the following sentences depending on whether its antecedent occurs in the smallest TP containing it or not:

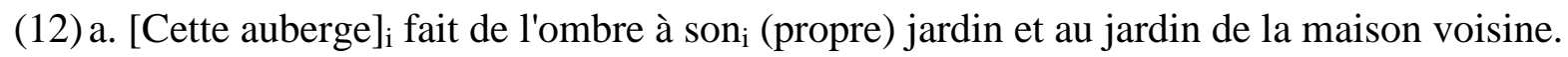

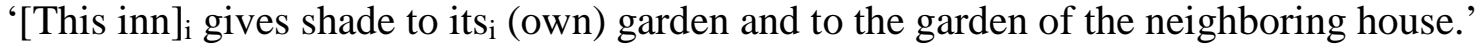

b. [Cette auberge $]_{\mathrm{i}}$ bénéficie du fait que ${ }_{\mathrm{T}} \operatorname{son}_{\mathrm{i}}\left({ }^{*}\right.$ propre) jardin est plus spacieux que celui des auberges voisines].

'[This inn $]_{\mathrm{i}}$ benefits from the fact that ${ }_{\mathrm{TP}} \mathrm{its}_{\mathrm{i}}\left({ }^{*} \mathrm{Own}\right)$ garden is more spacious than that of the neighboring inns].'

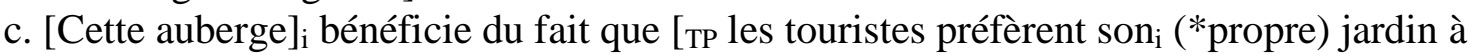
ceux des auberges voisines].

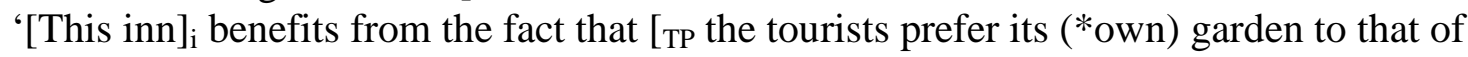
the neighboring inns].'

In (12a), son propre and its antecedent cette auberge ('this inn') belong to the same TP and the sentence is natural. However in (12b) and (12c), the antecedent cette auberge is the subject of the main clause while son propre occurs in the embedded clause (subject in (12b), 
object in (12c)), which means that the antecedent is outside the smallest TP containing son propre, and the sentence is degraded. This shows that the local binding domain must at most be the tensed TP containing the anaphor.

This is so whatever type of proposition is involved as exemplified by the following pairs of sentences: (12) is a complement TP while (13) and (14) exhibit cases of adjunct TP and the same contrast obtains, i.e. the sentence is degraded when the antecedent does not occur in the smallest TP including son propre.

(13)a. [Cette montagne $]_{\mathrm{i}}$ est moins réputée pour son $_{\mathrm{i}}$ (propre) sommet que pour le sommet voisin auquel elle donne accès.

'[This mountain $]_{i}$ is less renowned for its $\mathrm{s}_{\mathrm{i}}(\mathrm{own})$ summit than for the neighboring summit it gives access to.'

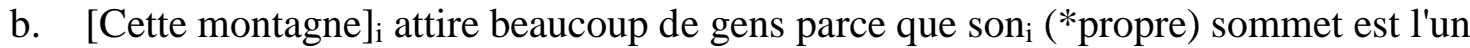
des sommets les plus escarpés du pays.

'[This mountain $]_{\mathrm{i}}$ attracts many people because its ${ }_{\mathrm{i}}$ (*own) summit is one of the steepest summits in the country.'

(14)a. [Ce problème $]_{\mathrm{i}}$ inclut sa $\mathrm{a}_{\mathrm{i}}$ (propre) solution et celle du problème précédent.

'[This problem $]_{\mathrm{i}}$ includes its $\mathrm{s}_{\mathrm{i}}$ (own) solution and that of the previous problem.'

b. [Ce problème $]_{\mathrm{i}}$ présente peu de difficultés pour que les élèves puissent trouver $\mathrm{sa}_{\mathrm{i}}$

(*propre) solution plus rapidement que celle des problèmes précédents.

'[This problem $]_{\mathrm{i}}$ presents few difficulties so that the students can find its ${ }_{\mathrm{i}}{ }^{*}$ own) solution more quickly than that of the previous problems.'

The same contrast obtains with non-finite TPs:

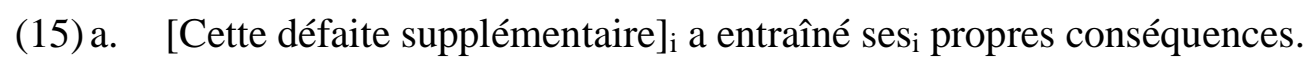

'[This additional defeat $]_{i}$ entailed its $s_{i}$ own consequences.'

b. [Cette défaite supplémentaire $]_{\mathrm{i}}$ a poussé les habitants à supporter ses $\mathrm{i}_{\mathrm{i}}$ (*propres) conséquences en plus de celles de l'occupation.

'[This additional defeat $]_{\mathrm{i}}$ led the inhabitants to endure its ${ }_{\mathrm{i}}{ }^{*}$ own $)$ consequences on top of those of the occupation.'

In (15b), ses propres occurs in an infinitival clause containing a subject (i.e. PRO controlled by les habitants ('the inhabitants')) while the antecedent cette défaite supplémentaire ('this additional defeat') is the subject of the matrix clause, i.e. is outside of the infinitival clause; in this case, the sentence is degraded, as opposed to (15a) where ses propres and the antecedent occur in the same TP. Also, note that this is not due to an intervention effect with the animate les habitants ('the inhabitants') since it has been shown in (11) that inanimate son propre is not subject to such intervention effects.

Similarly, the contrast in (16) shows that a small clause also constitutes a binding domain:

(16) a.[Cette peinture] $]_{i}$ possède ses ${ }_{i}$ (propres) composants et des composants plus communs. '[This paint $]_{\mathrm{i}}$ includes its $\mathrm{s}_{\mathrm{i}}$ own components and more common components.'

b. [Cette peinture $]_{i}$ a rendu les ouvriers allergiques à ses ( $^{*}$ propres) composants et à ceux d'un autre type de peinture similaire.

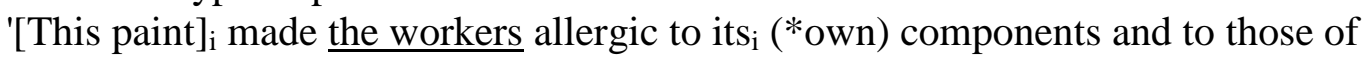
another type of similar paint.' 
In (16b), the subject of the small clause les ouvriers ('the workers') intervenes between ses propres and the antecedent cette peinture ('this paint') subject of the matrix clause; the sentence is degraded unlike (16a) that does not involve any small clause.

Finally, the same holds if son propre sits in a DP with a subject (distinct from the anaphor): ${ }^{14}$

(17)a. [Cette entreprise $]_{i}$ suscite l'admiration de son $_{i}$ (propre) patron et la colère des patrons concurrents.

'[This company $]_{i}$ arouses the admiration by its $s_{i}(\mathrm{own})$ manager and the anger of the competing managers.'

b. [Cette entreprise $]_{\mathrm{i}}$ suscite l'admiration des employés pour son ${ }_{\mathrm{i}}\left({ }^{*}\right.$ propre $)$ patron et leur colère contre les patrons concurrents.

'[This company $]_{i}$ arouses the admiration of the employees for its ${ }_{i}\left({ }^{*}\right.$ own $)$ manager and their anger against the competing managers.'

c. [Cette entreprise $]_{i}$ suscite votre admiration pour son ( $^{*}$ propre) patron et votre colère contre les patrons concurrents.

'[This company $]_{\mathrm{i}}$ arouses your admiration for its ${ }_{\mathrm{i}}\left({ }^{*} \mathrm{own}\right)$ manager and your anger against the competing managers.'

In (17b) and (17c), son propre is part of a DP with subject and its antecedent is outside this $\mathrm{DP}$; in other terms, the subject of the DP les employés ('the employees') in (17b) or votre ('your') in (17c) blocks the dependence between son propre and its antecedent, which makes the sentence unacceptable. This contrasts with (17a) where son propre appears in the same DP with no intervening subject.

All these pairs of examples demonstrate that inanimate possessor son propre is subject to locality, in the sense that it must be bound within a local domain corresponding to the smallest $\mathrm{XP}$ with an intervening subject containing it. This requirement has been illustrated using tensed TPs, infinitival TPs, APs and DPs.

This argues against the coargument view that predicts son propre to be exempt in all the previous sentences, thus not subject to syntactic requirements but only possibly to discourse constraints. But the case of inanimate son propre makes clear that we are not dealing with discourse constraints like point of view ${ }^{15}$ since such constraints should equally rule out inanimate son propre disregarding locality. In sum, the previous examples rehabilitate the classical binding theory against the coargument view in the following sense: the crucial notion

\footnotetext{
${ }^{14}$ Such cases constitute a problem if Reuland's 2011 view was extended to the French cases: in this view, syntactic predicates are redefined as having to have an event role (or e-role), and Ns are hypothesized not to have an event role. This problem is not manifest in Reuland (2011) as only himself, not itself, is examined. For English, it should be tested whether the antecedent must occur within the DP when itself appears in a DP with subject.

${ }^{15}$ It is not as clear that discourse constraints like accessibility (mentioned by Reinhart and Reuland 1993) could not play a role with respect to locality: thus Ariel (1990) suggests that both the saliency of the antecedent and the distance between the antecedent and the pronoun are crucial criteria for determining the accessibility of the antecedent. Assuming that inanimates are less salient than animates, this could give an explanation for why there is a correlation between locality and animacy. But first, this would still argue against the coargument view since adopting this kind of theory would make no use of coargumenthood. Moreover, the problem of this theory like other pragmatic theories of binding is that it predicts optionality and the possibility of overriding the rule if the context is manipulated; but this is not the case, there is no escape from structural constraints. As suggested by Ariel herself, discourse constraints like accessibility do not work at the level of sentences but rather at the level of discourse: accessibility may govern whatever optional decisions are left by the grammar. At the level of sentences, they may give an historical explanation of the grammaticalization process, i.e. how such systems of binding may have arisen.
} 
is not coargumenthood, but that of a structurally defined local domain in which the anaphor needs to be bound.

We thus conclude that the coargument view is too weak.

\subsection{Why the coargument view is too strong}

Not only is the coargument view too weak, it is also too strong.

Some versions predict that an anaphor occupying a coargumental position cannot be coindexed with anything other than a coargument. ${ }^{16}$ But the distribution of son propre in well-formed examples like the following demonstrates that this is incorrect.

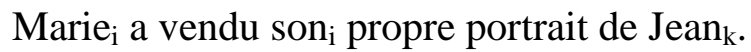

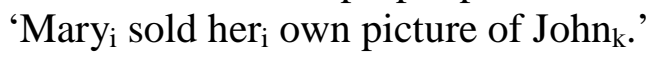

In (18), son propre ('her own') is a coargument of Jean ('John') but takes Marie as antecedent. This possibility is not problematic under Reuland (2011)'s theory since N's not having an event role, e.g. portrait ('picture'), do not qualify as the relevant kind of predicate, and son propre is exempt. But according to Pollard and Sag (1992) or Reinhart and Reuland (1993), coindexation should, wrongly, be excluded with anything other than Jean.

Under Reinhart and Reuland (1993)'s theory it could be objected that the anaphor is a focused anaphor in this case and this is why it is exempt given that a focused anaphor moves at LF to a non-argumental position. However, this would predict that possessor son propre should always be exemptable from condition A. This is not the case however, as shown in the previous subsections: inanimate son propre is subject to syntactic restrictions of locality; and it is not sufficient to add discourse constraints to solve the weakness of the prediction; the notion of syntactic locality must be modified. We conclude that the proposals of Pollard and Sag (1992) or Reinhart and Reuland (1993) at the very least must be amended.

As for Reuland's 2011 proposal, the scope of condition A is limited to applying to coarguments of verbs - the only elements having an event role. Whether this proposal is too strong can't be shown by using son (propre), which is a nominal argument. By examining the behavior of elle-même in the next section 3, we will show that it too is too strong.

\section{Arguments from elle-même}

\subsection{Elle-même and locality}

Like son propre, elle-même (lit. her-same/even; close to herself but not quite the same) is not standardly described as an anaphor. For instance, Zribi-Hertz (1995) assumes that elle-même is specific in that it is a bindable expression unspecified for locality and disjoint reference (which makes very weak predictions).

The behavior of elle-même becomes clearer if we take into account inanimacy, as we did for son propre. Indeed, elle-même is subject to locality if it is inanimate but not if it is animate. This is illustrated by the following sentences using clausemateness:

(19)a. [La Terre $]_{\mathrm{i}}$ tourne autour d'elle $\mathrm{i}^{-}$(même).

\footnotetext{
${ }^{16}$ Under Reinhart and Reuland's version, one of the coarguments should be a subject. This is the case in example (18). Note that coindexing is required but may not, of course, be sufficient as further constraints, e.g. on the antecedent may be relevant. Sentence (18) however is fine.
} 
'[The earth $]_{\mathrm{i}}$ revolves around $\mathrm{it}_{\mathrm{i}}{ }^{*}$ (self).'

b. [La Terre $]_{i}$ subit l'effet gravitationnel des nombreux satellites qui tournent autour d'elle in $^{*}$ *même).

'[The earth $]_{\mathrm{i}}$ is subject to the gravitational effect of the numerous satellites that revolve around $i_{i}\left({ }^{*}\right.$ self).'

c. De son point de vue, Marie $e_{i}$ souffre de la présence des nombreuses personnes qui tournent autour d'elle $\mathrm{i}_{\mathrm{i}}$ (même).

'From her viewpoint, Mary ${ }_{i}$ suffers from the presence of many people that move around her ${ }_{i}\left({ }^{*}\right.$ self $)$.

Thus (19a) contrasts with (19b) because the inanimate antecedent la Terre ('the earth') is in the same proposition as elle-même in (19a) but not in (19b); this correlates with a contrast in grammaticality: elle-même is only acceptable in (19a). However, when the antecedent is animate as in (19c) (Marie), the sentence is acceptable even if elle-même is embedded in another clause. Thus inanimacy and locality correlate for elle-même, which suggests that it behaves like possessor son propre and like a plain anaphor when inanimate.

Moreover, inanimate elle-même supports the hypothesis that a plain anaphor must be bound within the smallest XP with an intervening subject containing it as argued for son propre. First, (20) illustrates the c-command requirement:

(20)a. [La Terre $]_{\mathrm{i}}$ tourne autour d'elle $\mathrm{i}^{-*}$ (même). ${ }^{17}$

'[The earth $]_{i}$ revolves around $i_{i}{ }^{*}($ self).'

b. Les satellites de [la Terre $]_{i}$ tournent autour d'elle ${ }_{i}\left({ }^{*}\right.$ même).

'The satellites of [the earth $]_{\mathrm{i}}$ revolve around $\mathrm{it}_{\mathrm{i}}\left({ }^{*} \mathrm{self}\right)$. '

Elle-même can take la Terre ('the earth') as antecedent when it c-commands it as in (20a), but not when it does not as in (20b).

As in the case of son propre, there is no subject orientation involved since the same holds when the antecedent occupies the object position instead of the subject position:

(21)a. J’ai roulé [le tapis] $]_{\mathrm{i}}$ sur luii $\mathrm{i}^{*}$ (même).

'I rolled [the carpet $]_{\mathrm{i}}$ on $\mathrm{it}_{\mathrm{i}}{ }^{*}$ (self).'

b. J'ai roulé les bords [du tapis] $]_{\mathrm{i}}$ sur luii $\mathrm{i}_{\mathrm{i}}\left({ }^{*}\right.$ même).

'I rolled the edges of [the carpet $]_{i}$ on $i_{i}{ }^{*}($ self).'

Like son propre, inanimate elle-même is not subject to intervention either: as far as the antecedent is in the local domain of elle-même, other elements can intervene between elle-même and the antecedent, whether animate and inanimate, singular or plural:

(22)a. [La Lune $]_{i}$ attire l’eau de la Terre/les océans vers elle ${ }_{i}$-même.

'[The moon $]_{\mathrm{i}}$ attracts the earth's water/the oceans to itself $f_{\mathrm{i}}$.'

b. [La Lune $]_{i}$ attire les êtres humains/l'homme vers elle ${ }_{i}$-même. '[The moon $]_{\mathrm{i}}$ attracts human beings/mankind to itself $\mathrm{f}_{\mathrm{i}}$ '

(23) shows that like inanimate son propre, inanimate elle-même does not license an antecedent outside the smallest tensed clause it occurs in, whatever the type of clause

\footnotetext{
${ }^{17}$ Note that the sentence with c-command of the antecedent is degraded in the absence of même (an effect of condition B) while a similar sentence with son propre is not degraded in the absence of propre.
} 
(complement clause in (23b) and (23c), adjunct clause in (23d) and (23e)) and whatever the position of elle-même is (subject in (23b) and (23e), object in (23c) and (23d)). ${ }^{18}$

(23) a. [La Terre $]_{\mathrm{i}}$ tourne autour d'elle $\mathrm{i}^{-*}$ (même).

'[The earth $]_{\mathrm{i}}$ revolves around $\mathrm{it}_{\mathrm{i}}^{*}$ (self).'

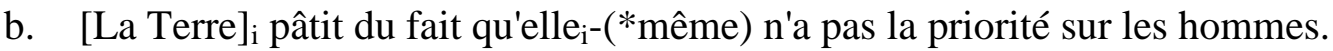

'[The earth $]_{\mathrm{i}}$ suffers from the fact that $\mathrm{it}_{\mathrm{i}}$ (*self) does not get priority on humans.'

c. [La Terre $]_{\mathrm{i}}$ subit le fait que de nombreux satellites tournent autour d'elle $\mathrm{e}_{\mathrm{i}}$ (*même).

'[The earth $]_{\mathrm{i}}$ suffers from the fact that many satellites revolve around $\mathrm{it}_{\mathrm{i}}\left({ }^{*}\right.$ self).'

d. [La Terre $]_{i}$ connaît le phénomène des marées en partie parce que la Lune tourne autour d'elle - $^{*}$ même).

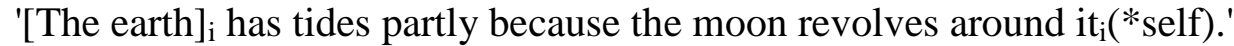

e. [La Terre $]_{i}$ est la seule planète bleue du système solaire parce que contrairement aux autres, elle $\mathrm{e}_{\mathrm{i}}\left({ }^{*}\right.$ même $)$ est dotée d'une atmosphère comportant du dioxygène et est recouverte d'eau liquide.

'[The earth $]_{\mathrm{i}}$ is the only blue planet of the solar system because contrary to the others, $\mathrm{it}_{\mathrm{i}}\left({ }^{*}\right.$ self $)$ has an atmosphere containing dioxygen and is covered by liquid water.'

Similar judgments obtain if elle-même appears in an infinitival clause while the antecedent is in the matrix clause. Thus in (24b), the PRO (controlled by les invités 'the guests') subject of the non-finite clause intervenes between le tapis ('the carpet') and elle-même; and in (24c), the subject les hommes ('humans') occurs between elle-même and the antecedent la Terre ('the earth'). Since elle-même is not in principle subject to intervention as illustrated in (22), this is a question of domain.

(24)a. [Le tapis $]_{\mathrm{i}}$ est enroulé sur lui ${ }_{\mathrm{i}}$-même.

'[The carpet $]_{\mathrm{i}}$ is rolled on itself $\mathrm{f}_{\mathrm{i}}$.'

b. Du fait de sa beauté, [le tapis] $]_{\mathrm{i}}$ n’incite pas les invités à marcher sur lui $\mathrm{i}_{\mathrm{i}}$ (*même), mais à côté.

'Because of its beauty, [the carpet] $]_{i}$ does not lead the guests to step on $\mathrm{it}_{\mathrm{i}}$ (*self), but on the side.'

c. [La Terre $]_{\mathrm{i}}$ ne peut pas rendre les hommes responsables d'elle $\mathrm{i}_{\mathrm{i}}\left({ }^{*} \mathrm{même}\right)$.

'[The earth $]_{i}$ cannot make humans responsible for it(*self).'

Finally, (25a) presents the same fact as above in a DP with subject, and (25b,c) in a PP with subject.

(25)a. [Cette loi $]_{\mathrm{i}}$ a provoqué la colère des habitants contre elle $\mathrm{e}_{\mathrm{i}}$-(??même) et contre ceux qui l'ont votée.

'[This law $]_{i}$ aroused the anger of inhabitants against it $t_{i}$ (??self) and those who voted for it.'

b. [Cette loi $]_{\mathrm{i}}$ a provoqué leur/notre colère contre elle-(??même) et contre ceux qui l'ont votée.

'[This law $]_{i}$ aroused their/our anger of inhabitants against it $\mathrm{i}_{\mathrm{i}}$ (??self) and those who voted for it.'

c. [L'enceinte du château $]_{i}$ cache les habitants derrière elle ${ }_{i}$-(??même). ${ }^{19}$

\footnotetext{
${ }^{18}$ Note that all the deviant sentences that follow in this section would be well formed if they were minimally modified to make the antecedent a (live) person.
} 
'[The wall of the castle $]_{i}$ hides the inhabitants against it

In both cases, the subject of the DP or PP les habitants ('the inhabitants') intervenes between elle-même and the antecedent, respectively cette loi ('this law') or l'enceinte du château ('the wall of the castle').

All these examples lead to the same conclusion as the sentences involving son propre: the domain relevant for anaphoricity appears to be the smallest XP with an intervening subject containing the anaphor.

\subsection{Elle-même and the coargument view}

Even if elle-même and son propre exhibit the same pattern with respect to locality and animacy, they do not argue against the coargument view in the same way: with elle-même, the argument about the weakness of the coargument view (too weak) is weaker, and the argument about its strength (too strong) is stronger.

First, elle-même does not make the same point as son propre because it is not always predicted to be exempt according to the coargument view. Recall that most cases of son propre are supposed to be exempt under predicate-based theories since it is the only argument of the nominal predicate it combines with (or Ns do not have an event role). This does not hold for elle-même which is an argument of a verb in many cases. Therefore, many of the previous ill-formed examples are correctly ruled out by the coargument view for one of the two following reasons: either they violate condition A as elle-même is not coindexed with a coargument while there is one (cf. e.g. (24b); or they fall under the case of nominative anaphora (cf. (23b,e)) which is excluded in different ways depending on the implementation of the coargument view. ${ }^{20}$

Therefore, the previous examples involving elle-même do not directly argue against the coargument view, they only do so if coupled with the sentences involving son propre because they exhibit the same locality and binding domain pattern.

But elle-même more directly argues against the coargument view too. First, the same holds as son propre when elle-même is the inanimate, single argument of a nominal predicate: it is predicted to be exempt by the coargument view but is actually subject to locality as illustrated by the following sentences:

(26)a. [Cette loi $]_{\mathrm{i}}$ a entraîné la publication d'un livre sur elle $\mathrm{i}_{\mathrm{i}}$-même et sur son auteur. '[This law] $]_{\mathrm{i}}$ led to the publication of a book about itself $\mathrm{i}_{\mathrm{i}}$ and its author.'

b. * [Cette loi $]_{\mathrm{i}}$ est si importante que les journalistes prédisent la publication d'un livre sur elle $\mathrm{e}_{\mathrm{i}}$-même et sur son auteur.

'*[This law $]_{\mathrm{i}}$ is so important that the journalists predict the publication of a book about itself $f_{\mathrm{i}}$ and its author.'

\footnotetext{
${ }^{19}$ Examples like this suggest that Ps can have subjects. Note that both Reinhart and Reuland (1993) and Reuland (2011) would make wrong predictions here: the former would incorrectly predict elle-même to be exempt because Ps do not have a subject according to them; the latter would predict so because Ps do not have an event role according to Reuland (2011).

${ }^{20}$ Pollard and Sag (1992) must stipulate a specific principle against nominative anaphors. Reinhart and Reuland (1993)'s theory invoke the Chain Condition (which plays other roles too): a maximal A-chain $\left(\alpha_{1}, . ., \alpha_{n}\right)$ contains exactly one link $-\alpha_{1}$ - that is both $+R$ and Case-marked.
} 
(27)a. [La Grande roue $]_{i}$ a éjecté les enfants au-dessus d'elle $e_{i}$-même. '[The big wheel $]_{\mathrm{i}}$ ejected the children above itself $\mathrm{f}_{\mathrm{i}}$.'

b. * [La Grande Roue $]_{\mathrm{i}}$ a été fermée après que des enfants ont été éjectés au-dessus

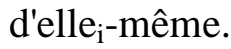

'*[The big wheel $]_{\mathrm{i}}$ has been closed after children got ejected above itself $\mathrm{f}_{\mathrm{i}}{ }^{\prime}$

(28)a. [Cette atrophie $]_{\mathrm{i}}$ tue tout, hormis elle ${ }_{\mathrm{i}}$-même.

'[This atrophy $]_{\mathrm{i}}$ kills everything except itself $\mathrm{f}_{\mathrm{i}}$.'

b. * [Cette atrophie $]_{\mathrm{i}}$ est très dangereuse parce que rien ne résiste à ce genre de problème

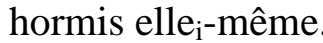

$' *[\text { This atrophy }]_{\mathrm{i}}$ is very dangerous because nothing resists to this kind of problem except itself ${ }_{\mathrm{i}}{ }^{\prime}$

(29) a. [Ces résultats $]_{\mathrm{i}}$ ont de la valeur en eux $\mathrm{i}_{\mathrm{i}}$-mêmes.

'[These results $]_{\mathrm{i}}$ have value in themselves ${ }_{\mathrm{i}}$.'

b. *[Ces résultats $]_{\mathrm{i}}$ sont prometteurs même si le chercheur ne reconnaît pas encore de valeur en eux $_{\mathrm{i}}$-mêmes.

'*[These results $]_{\mathrm{i}}$ are promising even if the researcher does not recognize value in themselves yet.' $^{\prime}$

In all these examples, elle-même is the single argument of a preposition (respectively sur, audessus de, hormis, en) and the PP is not an argument, but an adjunct. Under the coargument view, elle-même is therefore predicted to be exempt; note that as opposed to son propre, it is so even under the strict version of Reinhart and Reuland (1993) since these prepositional predicates lack a subject which make their arguments immune to condition A; this is also so under Reuland (2011)'s theory since these prepositional predicates do not have an event role. However in all these cases, (a) contrasts with (b): the sentence (a), in which elle-même and the antecedent are clausemate, is grammatical, but the sentence (b), in which they are not in the same clause but elle-même is embedded in an adjunct clause, is degraded. The coargument views are all too weak to explain such cases just as in the case of son propre.

Note however that this pattern is accounted for under the view defended here since elle-même is inanimate in these sentences and is not locally bound by its antecedent,

More importantly, the behavior of elle-même provides an additional and crucial argument as compared to son propre. It shows that it need not be coindexed with a coargument even if it is an argument of a verbal predicate. In other words, it shows that all PB theories are too strong. Recall that son propre demonstrates that some coargument views are too strong because even when it is an argument of a nominal predicate with other arguments (and a subject), it need not be coindexed with one of them (see section 2.1). But at least one version of the coargument view, namely Reuland 2011, suggests that predicates without any event argument (like most nominal predicates) are not subject to condition A (following the experimental study Runner and Kaiser, 2005; Pollard, 2005 makes the same point based on certain English dialects). However, animate elle-même shows the same pattern with respect to verbal - thus eventive - predicates:

(30)a. Marie ${ }_{i}$ s'inquiète souvent du fait que ses enfants dépendent d'elle $\mathrm{e}_{\mathrm{i}}$-même.

'Mary $\mathrm{y}_{\mathrm{i}}$ is often worried that her children depend on herself $\mathrm{f}_{\mathrm{i}}$ '

b. [L'avenir de Marie $\left.{ }_{\mathrm{i}}\right]_{\mathrm{k}}$ ne dépend pas d'elle-même $\mathrm{i}_{\mathrm{i}}$, mais de ses parents.

'[Mary,'s future] does not depend on herself $f_{\mathrm{i}}$, but on her parents.' 
In (30), elle-même is an argument of the verb dépendre de ('depend on') that has a distinct subject and is therefore subject to condition A according to all coargument views. Thus elle-même should be coindexed with its coargument but it is not. Nevertheless, there is no violation of condition A since the sentence is perfectly grammatical.

Recall however that focus can rescue such sentences under Reinhart and Reuland's 1993 or Reuland's 2011 theory: according to them, a focused anaphor moves at LF to a nonargumental position and is therefore exempt. If elle-même were a focused anaphor in (30a), it would correctly be predicted to be exempt and the sentence grammatical.

But note that this can be controlled for. For example, (30a) is perfectly well formed as an answer to the question 'Quand Marie ${ }_{i}$ s'inquiète-t-elle du fait que ses enfants dépendent $d^{\prime} e l l e_{i}$-même? (When is Mary ${ }_{i}$ worried that her children will depend on hersel $f_{i}$ ?)' where the focus both of the question and of the answer is on the temporal adjunct and answered by souvent (often) and not elle-même.

Furthermore, if focus was at play, inanimate elle-même should be able to behave the same, but this is not borne out:

(31)a. [La Terre $]_{i}$ est dégradée par les êtres humains même si leur avenir ne dépend que d'elle - (*même).

'[The earth $]_{\mathrm{i}}$ is degraded by human beings even if their future only depends on it $_{\text {i }}\left({ }^{*}\right.$ self $) . '$

b. Les habitants de [la Terre $]_{\mathrm{i}}$ dépendent d'elle ${ }_{\mathrm{i}}\left({ }^{*}\right.$ même $)$.

'The inhabitants of [the earth $]_{i}$ depend on it ${ }_{i}(*$ self $) . '$

Both sentences (with même) are degraded either because the inanimate antecedent is not in the local domain of elle-même in (31a) and does not c-command it in (31b).

We can summarize this discussion in the following table in which the highlighted areas are problematic for PB views:

\begin{tabular}{|c|c|c|c|c|}
\hline \multirow{2}{*}{\begin{tabular}{|l|} 
Anaphor \\
Position \\
\end{tabular}} & \multicolumn{2}{|l|}{ Animate } & \multicolumn{2}{|l|}{ Inanimate } \\
\hline & exempt & non-exempt & exempt & non-exempt \\
\hline Predicted & $\begin{array}{l}\text { not subject to } \\
\text { locality }\end{array}$ & subject to locality & $\begin{array}{l}\text { not subject to } \\
\text { locality }\end{array}$ & $\begin{array}{l}\text { subject to } \\
\text { locality }\end{array}$ \\
\hline \multirow[t]{3}{*}{ Fact } & $\begin{array}{l}\text { not subject to } \\
\text { locality }\end{array}$ & $\begin{array}{l}\text { not subject to } \\
\text { locality }\end{array}$ & subject to locality & $\begin{array}{l}\text { subject to } \\
\text { locality }\end{array}$ \\
\hline & $\mathrm{OK}$ & $*$ & $*$ & $\mathrm{OK}$ \\
\hline & & theory too strong & theory too weak & \\
\hline
\end{tabular}

In sum, elle-même strongly supports the arguments based on son propre against the PB coargument views. First, it exhibits the same correlation between locality and inanimacy as son propre, thus corroborating the relevance of inanimacy as an independent diagnostic to test for locality. Next, it confirms the hypothesis that the local domain in which an anaphor must be bound is the smallest XP with an intervening subject containing it. Finally, it demonstrates that the coargument view is too strong since even in the case of verbal - thus eventive predicates, elle-même need not be coindexed with a coargument. 


\section{Inclusive reference: corroborating the plain/exempt dichotomy}

We claim that the domain within which a plain anaphor must be bound is (close to) what Chomsky (1986) proposes and distinct from what predicate based theories propose.

This claim is supported by an analysis of the behavior of possessor son propre and of ellemême. This analysis leads to separating differently from PB theories anaphors that are plain from anaphors that are exempt.

In this section, we discuss three questions:

1. Is there independent evidence that these expressions ought to be anaphoric?

2. Has independent evidence been convincingly adduced corroborating the dichotomy between plain and exempt anaphors defended by PB theories?

3. Is there in fact independent evidence corroborating the dichotomy between plain and exempt anaphors defended by PB theories?

We will answer positively the first and third questions, and negatively the second one.

\subsection{Son propre and elle-même: intrinsically anaphoric}

Our argumentation could be objected to on the grounds that it crucially relies on the behavior of elements, namely son propre and elle-même, not standardly known to be anaphors and thus possibly not anaphoric. But there are strong a priori grounds to expect that these expressions are run-of-the-mill anaphors on the basis of their internal make up. Indeed, it is an extensively documented pattern (cf. König, 2005) that, in language after language, affixing an intensifier or a focus particle to a pronoun turns it into a complex anaphor (e.g. him $\rightarrow$ himself). This is precisely what is found in French with each of the two expressions under consideration. Indeed, the internal structure of son propre makes it similar to complex SELF anaphors in Reinhart and Reuland's 1993 terminology: it is complex as it comprises a pronoun (son, just like him in himself) combined with another element (propre, like self in himself) whose effect is to intensify or create focal alternatives on the denotation of this pronoun (see Charnavel, 2012, chapters 1 and 2, for detailed discussion). This is also true of elle-même (lit. hersame/even) comprised of a pronoun elle and the focus particle/intensifier même (and ellemême, much like English himself, can be used as an intensifier). Thus, from the point of view of internal makeup, both conform to a well-attested structural schema for anaphors.

In addition, both of these expressions are referentially defective in Reinhart and Reuland's 1993 sense in that neither can freely refer to some previously mentioned entity in the world the way, say, bare pronouns can. ${ }^{21}$

Finally, it is remarkable that the locality restrictions on elle-même and son propre not only are similar, but duplicate what has long been claimed by classical binding theories about plain anaphor binding.

We thus conclude that there are excellent a priori reasons to take the behavior of such expressions as revealing the restrictions imposed by Condition A of the binding theory.

\subsection{Non correlations}

\footnotetext{
${ }^{21}$ We know this because inanimate son propre or elle-même can't be used only with a discourse introduced antecedent.
} 
Still we simultaneously base on son propre and elle-même the argument against PB views of anaphors and show that they are anaphors. To minimize the effects of decisions driven by theory internal considerations, it is necessary to provide criteria corroborating the plain/exempt status of anaphors independent of their binding behavior.

Let us ask what the plain/exempt dichotomy corroborates with in PB theories. Different PB theories make different claims. For Pollard and Sag (1992), positions allowing plain anaphors disallow pronouns with the same antecedents. While for Reinhart and Reuland (1993), plain anaphors must be semantically bound (that is must be interpreted as bound variables) while exempt anaphors do not have to. Under scrutiny, neither of these correlations holds, as we now show, making the proposed split between plain and exempt anaphors internal to these BP theories.

First, unlike what is claimed in Pollard and Sag (1992) there is no overall complementarity between plain anaphors and pronouns. This can be seen in two ways. First we would expect that in a context in which a pronoun has coarguments and cannot take one of them as antecedent, a plain anaphor with that antecedent should be allowed. But this is incorrect as the following example shows:

(32). *John and Mary like him/himself.

Here, neither him nor himself (which is a plain anaphor in their view, having the subject as coargument) are allowed with John as antecedent. This suggests that syntactic coargumenthood is not sufficient to explain the joint distribution of pronouns and plain anaphors. $^{22}$

Conversely, there are cases in which both a plain anaphor and a pronoun are allowed with the same antecedent. This is illustrated e.g. in the following type of examples discussed in Heim (1998): ${ }^{23}$

(33) Every boy thinks that only he destroyed him/himself.

Here both the pronoun and the anaphor are allowed, albeit with different meanings (resp. every boy thinks that nobody but him destroyed him and every boy thinks that he alone self destructed).

Similarly, unlike what is claimed in Reinhart \& Reuland (1993, p. $673 \mathrm{ff}$ ), it is far from clear that plain anaphors must be semantically bound, that is, interpreted as bound variables. ${ }^{24}$ Thus both English sentences below allow strict and sloppy readings, readily for the first one (see e.g. Hestvik, 1995, Kehler, 2005), for many speakers for the second (see e.g. Büring, 2005, p. 141):

John $_{\mathrm{i}}$ defended himself ${ }_{\mathrm{i}}$ before Bill did.

$=\ldots$ before Bill defended himself (sloppy)

$=\ldots$ before Bill defended him

\footnotetext{
${ }^{22}$ An observation exploited by Reinhart and Reuland (1993) or Reuland (2011) who take the distribution of pronouns to be sensitive to semantic coargumenthood, unlike that of plain anaphors which are sensitive to syntactic coargumenthood.

${ }^{23}$ Reinhart and Reuland (1993) provide other cases.

${ }^{24}$ This point is noted in Hestvik (1995).
} 


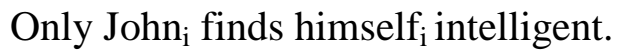

$=$ Only John $_{\mathrm{i}} \lambda \mathrm{x}$ (x finds $\mathrm{x}$ intelligent) (sloppy)

$=$ Only John $_{\mathrm{i}} \lambda \mathrm{x}$ (x finds John intelligent) (strict)

As standardly assumed, the availability of such strict readings reveals that these plain anaphors do not have to be interpreted as bound variables: they may well be required to be syntactically bound, but not semantically bound.

This lack of independent correlation is particularly troublesome: because of the way they are set up - defining the plain/exempt dichotomy in terms of syntactic positions - the PB binding theories we discuss entail that plain and exempt anaphors are in complementary distribution. And indeed, in cases in which these PBBTs predict that anaphors are exempt, examples are provided showing that distant (non coarguments) or non c-commanding antecedents are allowed, e.g. (from Pollard and Sag, 1992, cited in Reuland, 2011):

Bill $_{\mathrm{m}}$ thought that nothing could make [a picture of himself $\mathrm{m}_{\mathrm{m}}$ in the Times] acceptable to Sandy

Because the plain/exempt anaphor distinction is not correlated with any other property, it is difficult to assess the validity of such arguments. Indeed, such reasoning shows that such anaphors CAN be exempt, not that they MUST be. While there would probably be no disagreement in such examples as (36) concerning the status of the reflexive as exempt (as the antecedent is quite remote), the question becomes crucial when dealing with such examples as:

(37)a. They like pictures of themselves

b. They put food near themselves

These cases are analyzed as *necessarily* cases of exempt anaphora (contra what we propose) in PB approaches, in effect without any non theory internal argument. Unless some correlating property can be used, such arguments strike us as flawed. Given our proposal, the reflexives in such cases could be either plain or exempt (although detecting plain-ness with animates will be tricky given that exempt anaphors look like they have a strictly wider distribution than plain anaphors).

\subsection{Inclusive reference}

We now show that the plain/exempt dichotomy we propose does correlate with an independent property, namely the (im)possibility of inclusive reference.

Inclusive reference corresponds to cases where the reference of an anaphor is included in (cf. partial binding) or includes (cf. split antecedent) the reference of the antecedent (cf. a.o.

Lasnik: 1989; Den Dikken et al.: 2001). The coargument views that we are discussing predict inclusive reference to be impossible with non-exempt anaphors because, as known for a long time, syntactic binding imposed by condition $\mathrm{A}$ is interpreted as referential identity, ${ }^{25}$ either

\footnotetext{
${ }^{25}$ We are of course not considering reciprocal expressions (but we believe referential identity is also required for reciprocals in the following sense: in e.g. they like each other, which we take means roughly: Each of them likes an other of them, the sets over which each and other range, namely them must be identical to \|they\|, where they is the antecedent of the reciprocal.
} 
through coreference or semantic binding (the choice being regulated by Reinhart and Grodzinsky’s 1993 rule I - or some descendant of it, see e.g. Roelofsen, 2010). Exempt anaphors on the other hand are assumed (correctly so in our view) to allow partial binding.

This pattern is illustrated below.

(38) a. $\quad$ Jean $_{\mathrm{i}}$ a dit à Pierre $\mathrm{m}_{\mathrm{m}}$ que personne d'autre qu'eux-mêmes ${ }_{\mathrm{i}+\mathrm{m}}$ ne devrait faire ça $\mathrm{John}_{\mathrm{i}}$ told Bill $\mathrm{m}_{\mathrm{m}}$ that no one but themselves $\mathrm{i}_{\mathrm{i}+\mathrm{m}}$ should do this.

b. $\quad$ Ce décret ${ }_{\mathrm{i}}$ détourne la loi $\mathrm{i}_{\mathrm{m}}$ de lui-même $\mathrm{i}_{\mathrm{i}}$ d'elle-même $_{\mathrm{m}} /$ *d'eux-mêmes $_{\mathrm{i}+\mathrm{m}}$ This decree divert the law from itself/ from themselves ${ }_{i+m}$.

c. $\quad \operatorname{Jean}_{\mathrm{i}}$ et Marie pensaient que personne d'autre que lui-même ${ }_{i}$ ne devrait faire ça. $\left[\mathrm{John}_{\mathrm{i}} \text { and Mary }\right]_{\mathrm{m}}$ thought that no one but himself $\mathrm{i}_{\mathrm{i}}$ should do this.

d. $\quad$ [La terre et le soleil $\left.]_{\mathrm{i}}\right]_{\mathrm{m}}$ dépendent d'eux-mêmes ${ }_{\mathrm{m}} / *$ de lui-même ${ }_{\mathrm{i}}$ pour leur énergie.

The earth and the sun rely on themselves/ itself for their energy.

(38a) and (38b) are instances of split antecedence: the reference of eux-mêmes (themselves) is the sum of the reference of the two antecedents John and Bill in (38a) and the decree and the law in (38b). Thus eux-mêmes (themselves) is not coindexed with any coargument in (38a) as it does not have any coargument (it is a subpart of an argument of faire); therefore, themselves is exempt under PB theories and ours too since it is animate and (38a) is correctly predicted to be acceptable. In (38b), eux-mêmes (themselves) is inanimate: therefore it cannot be exempt (under any theory: for PB theories because it is in (verbal) coargumental position; for us because it is inanimate). However, it is not locally bound as required by condition A or by PB theories: (38b) is correctly predicted to be unacceptable. Exactly the same obtains, mutatis mutandis for (38c) and (38d) with partial binding.

In other words, on uncontroversial cases, (non)-exemption correlates with (non)-inclusive reference.

We will now see that on controversial cases, it correlates with our version of (non)-exemption.

Inclusive reference is a particularly interesting criterion because there is no reason, other than formal, why it should be allowed or disallowed. In particular, interpretive constraints on what can act as the antecedent of an exempt anaphor (e.g. denote a live person or some other discourse conditions) should be irrelevant.

The interesting cases are of course cases in which different theories make different predictions regarding exemption. We should examine four types of cases, cases we claim should not be classified as exempt, but are by $\mathrm{PB}$ theories ${ }^{26}$ both for possessor son propre and elle-même, and both with inanimates and animates: ${ }^{27}$

\footnotetext{
${ }^{26}$ There are no converse cases as the classical theory is strictly more permissive than PB theories regarding Condition A.

${ }^{27}$ A priori, we should also distinguish partial binding and split antecedence but since they behave the same we put them under the same rubric of inclusive reference.
} 


\begin{tabular}{|l|l|l|l|l|}
\hline & \multicolumn{2}{|c|}{$\mathbf{1}$} & \multicolumn{1}{c|}{$\mathbf{2}$} & \multicolumn{1}{c|}{$\mathbf{3}$} \\
\hline $\mathbf{1}$ & \multicolumn{2}{|c|}{ Classically non exempt but PB exempt positions } & Inanimate & Animate \\
\hline $\mathbf{2}$ & Inclusive Reference: & son propre & OK & OK \\
\cline { 3 - 5 } $\mathbf{3}$ & PB theories predictions & elle-même & OK & OK \\
\hline $\mathbf{4}$ & $\begin{array}{l}\text { Inclusive Reference: } \\
\text { our predictions }\end{array}$ & son propre & $*$ & OK \\
\hline $\mathbf{5}$ & & elle-même & $*$ & OK \\
\hline
\end{tabular}

Here the French data clearly support our analysis. We correctly predict that line 4 and 5 or the table above are what should be observed, and not lines 2 and 3 as PB theories do.

Indeed, consider inanimate son propre first when it is the only argument of the nominal predicate it combines with. Recall it is predicted to be (wrongly) excluded by Reinhart and Reuland's 1993 theory. But for Pollard and Sag's 1992 and Reuland's 2011 PB theories, it is predicted to be exempt for different reasons (either because son does not have a coargument, or because nominals lack an event argument). . Therefore, it should be able to exhibit inclusive reference in such cases. This prediction is not borne out as illustrated by the following examples:

(40) a. [Context: The school has a garden, but the teachers' houses do not]

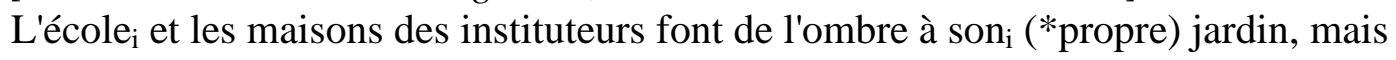
pas au jardin de la mairie.

'The school ${ }_{\mathrm{i}}$ and the teachers' houses give shade to its ${ }_{\mathrm{i}}{ }^{*}$ own) garden, not to the garden of the town hall.' $\quad$ [\|son propre $\|\subset\|$ antecedent $\|]$

b. [Context: The school and the teachers' houses have a common garden.]

L'école $_{i}$ fait de l'ombre à leur ${ }_{i+m}$ (*propre) jardin, mais pas au jardin de la mairie. 'The school ${ }_{i}$ gives shade to their $r_{i+m}\left({ }^{*}\right.$ own $)$ garden, not to the garden of the town hall.’

[ $\|$ antecedent $\|\subset\|$ son propre $\|]$

c. [Context: The school and the teachers' houses have each a garden.]

L'école $_{i}$ fait de l'ombre à leurs ${ }_{i+m}$ (*propres) jardins, mais pas au jardin de la mairie.

'The school gives shade to their $_{\mathrm{i}+\mathrm{m}}\left({ }^{*}\right.$ own) gardens, not to the garden of the town hall.'

[ $\|$ antecedent $\|\subset\|$ son propre $\|]$

In all (41a, b, c) involving inclusive reference, son propre is predicted to be exempt by the coargument view since it does not have any coargument. But in none of them is it acceptable whether it is an instance of partial reference as in (41a) or an instance of split reference as in (41b) and (41c).

Once again, the animacy dimension plays a crucial role. If we modify the sentences in (41) to make the anaphor animate, inclusive reference becomes possible again:

(41)a. [Context: The mayor has a garden, but the teacher does not]

Le maire ${ }_{i}$ et l'institutrice s'occupent de son $_{i}$ (propre) jardin, et non pas de celui de l'institutrice.

'The (he-)mayor ${ }_{\mathrm{i}}$ and the (she-)teacher take care of to his ( $\left._{\mathrm{i}}^{*} \mathrm{own}\right)$ garden, and not of the teacher's.'

[ $\|$ son propre $\|\subset\|$ antecedent $\|]$

b. [Context: The mayor and the teachers have a common garden.] 
Le maire ${ }_{i}$ s'occupe de leur $_{i+m}$ (propre) jardin, et non du jardin du pompier.

'The mayor $r_{i}$ takes care of their $r_{i+m}$ (own) garden, and not of the fireman's.'

c. [Context: The mayor and the teacher each have a garden.]

[ $\|$ antecedent $\|\subset\|$ son propre $\|]$

Le maire ${ }_{i}$ s'occupe de leurs $_{i+m}$ (propres) jardins, et non pas du jardin du pompier.

'The mayor $_{\mathrm{i}}$ takes care of their $\mathrm{r}_{\mathrm{i}+\mathrm{m}}$ (own) gardens, and not of the fireman's.'

$$
\text { [ } \| \text { antecedent }\|\subset\| \text { son propre } \|]
$$

The same pattern is found with elle-même. In each of the following cases, illustrating what we take to be non-exempt positions, an inanimate cannot be partially bound - (43a) -or allow split antecedents - (43b):

(42)a. * L'école ${ }_{i}$ et le musée ressemblent aux photos d'elle-même ${ }_{i}$.

'The school ${ }_{\mathrm{i}}$ and the museum look like pictures of itself $f_{\mathrm{i}}$.'

b. * Le musée ressemble aux photos d'eux-mêmes $_{\mathrm{i}+\mathrm{m}}$.

[ $\|$ elle-même $\|\subset\|$ antecedent $\|]$

'The museum ${ }_{i}$ looks like pictures of themselves $_{i+m}$.'

But selecting animate antecedents makes such cases fine:

$[\|$ antecedent $\|\subset\|$ eux-mêmes $\|]$

(43)a. Marie $e_{i}$ et son fils ont imprimé des photos d'elle-même ${ }_{i}$.

'Marie ${ }_{\mathrm{i}}$ and her son John printed pictures of herself $\mathrm{i}_{\mathrm{i}}$ '

b. Jean J imprimé des photos d'eux-mêmes $_{\mathrm{i}+\mathrm{m}}$.

$$
\text { [ } \| \text { elle-même }\|\subset\| \text { antecedent } \|]
$$

'John printed pictures of themselves $_{i+m}$.'

$$
\text { [\|antecedent }\|\subset\| \text { eux-mêmes } \|]
$$

We thus see that cases of inclusive reference strictly corroborate the idea that inanimates son propre and elle-même are plain anaphors in such cases, and therefore also corroborate the plain/exempt dichotomy we propose: such cases thus supports the idea that their distributions are regulated by the classical condition A.

\subsection{Summary of Empirical Findings}

To sum up, the cases of inanimate possessor son propre and elle-même demonstrate that coargument theories of binding are too strong and too weak: too strong because even in the presence of a coargument, such anaphors can be exempt (when animate); too weak because even when predicted to be exempt, inanimate son propre and elle-même obey syntactic requirements of locality.

Furthermore, the notion of locality can be independently defined drawing on two independent diagnostics, namely inanimacy and inclusive reference. The former is meaning based, and related to what can qualify as an antecedent for an exempt anaphor. The latter is formal, and results from what Condition A of the binding theory requires of the relation between such plain anaphors and their antecedents, namely referential identity.

It is worth pointing out that the inanimacy/no inclusive reference/plain anaphor status correlation makes the proposal briefly mentioned in fn 13 according to which two different kinds of exemption could be involved even more implausible: a tripartite partition would make it mysterious why these factors correlate. 


\section{Residual Cases of Excluded Anaphors}

As we saw, we a priori expect that an animate anaphor can always be exempt if an antecedent of the right kind in terms of intrinsic content and discourse role is available. But this looks incorrect as shown by the following minimal pair:

(44)a. Marie ${ }_{i}$ s'inquiète souvent du fait que ses enfants dépendent d'elle $\mathrm{e}_{\mathrm{i}}$-même.

'Mary $y_{i}$ is often worried that her children depend on herself $f_{i}$.'

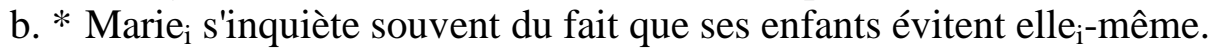

'Mary $\mathrm{y}_{\mathrm{i}}$ is often worried that her children avoid herself $\mathrm{i}_{\mathrm{i}}$.'

The first example is the type of examples we used to show that PB theories are too strong in requiring that coargumental anaphors could not be exempt as indeed elle-même both has a subject coargument and is exempt. But the ill-formedness of the second example is unexpected as the antecedent is identical in all relevant respects to that found in the first example, which, obviously, meets the relevant requirements for anteceding an exempt anaphor, whatever these requirements may be.

While (48b) might initially be taken to support PB theories in requiring that an anaphor with coargument takes a coargument as antecedent, the following pair shows that some other factor is at play:

(45) a. * Jean ${ }_{\text {i }}$ pense que Marie examinera lui $\mathrm{i}_{\mathrm{i}}$-même.

' $\mathrm{John}_{\mathrm{i}}$ thinks that Marie will examine himself $\mathrm{i}_{\mathrm{i}}$ '

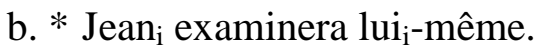

'John will examine himself.'

Indeed, even if lui-même is locally bound, the sentence remains unacceptable: requiring a coargument binder is not the relevant factor (as the contrast between the French examples and the English glosses also shows).

This raises two questions:

a. What excludes the French example?

b. Why do French and English behave differently?

We believe the answer to the first question is revealed by the following paradigm showing that the unacceptability of lui-même (read without narrow focus contrast on lui-même) in simple clauses correlates with the acceptability of the reflexive clitic se in the a/b pairs

(47)a. * Jean ${ }_{\mathrm{i}}$ examinera lui $\mathrm{i}_{\mathrm{i}}$-même.

'John $n_{\text {i }}$ will examine himself ${ }_{\mathrm{i}}$.'

b. Jean $_{\mathrm{i}} \mathrm{S}_{\mathrm{i}}$ 'examinera. ${ }^{28}$

' $\mathrm{John}_{\mathrm{i}}$ will examine himself $\mathrm{i}_{\mathrm{i}}$ '

(48)a. ??Jean ${ }_{\mathrm{i}}$ décrit le paysage à lui ${ }_{\mathrm{i}}$-même.

'John ${ }_{i}$ describes the landscape to himself ${ }_{i}$.'

\footnotetext{
${ }^{28}$ We say that se stands for an argument and use an index on it to facilitate presentation, without any claims about its actual role.
} 
b. $\mathrm{Jean}_{\mathrm{i}} \mathrm{se}_{\mathrm{i}}$ décrit le paysage.

' $\mathrm{John}_{\mathrm{i}}$ describes the landscape to himself $\mathrm{f}_{\mathrm{i}}$.'

(49)a. Marie ${ }_{i}$ dépend d'elle ${ }_{i}$-même.

'Mary depends on herself $_{\mathrm{i}}$ '

b. * Marie $\mathrm{se}_{\mathrm{i}}$ dépend.

'Mary ${ }_{i}$ depends on herself $f_{i}$ '

(50) a. Marie a présenté Jean ${ }_{\mathrm{i}}$ à $_{\text {lui }}$-même ${ }_{\mathrm{i}}$.

'Mary introduced John ${ }_{\mathrm{i}}$ to himself $\mathrm{i}_{\mathrm{i}}$ '

b. Marie ${ }_{\mathrm{k}} \mathrm{S} *_{\mathrm{i} / \mathrm{k}}$ 'est présenté Jean ${ }_{\mathrm{i}}$.

'Maryk introduced John ${ }_{\mathrm{i}}$ to himself herself $_{\mathrm{k}}$.

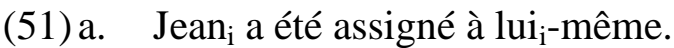

'John ${ }_{\mathrm{i}}$ has been assigned to himself $\mathrm{i}_{\mathrm{i}}$.'

b. * Jean $\mathrm{s}_{\mathrm{i}}$ 'a été assigné

'John ${ }_{\mathrm{i}}$ has been assigned to himself ${ }_{\mathrm{i}}$ ',

Taking se to be the missing argument, ${ }^{28}$ it is well known that it can only stand for a dative or an accusative object, it must be deep-subject oriented, and is incompatible with passive voice (see, e.g. Sportiche, in press, for recent discussion and references). In all such simple clause cases (the a/b pairs), se and lui-même are in complementary distribution. Se can stand for a direct object with subject antecedent $(51 \mathrm{a} / \mathrm{b})$, or an indirect object with subject antecedent $(52 \mathrm{a} / \mathrm{b})$ : in such cases, lui-même is excluded. Se is unavailable with other complements $(53 \mathrm{a} / \mathrm{b})$, with an indirect object with non subject antecedent $(54 \mathrm{a} / \mathrm{b})$ or in the presence of passive voice $(55 \mathrm{a} / \mathrm{b})$ : in all such cases lui-même is perfectly acceptable.

In such cases, this suggests that lui-même is in competition with the pronominal clitic se in the sense that only if se is not allowed to occur is lui-même allowed by itself. ${ }^{29}$ This type of competition is not limited to anaphors such as lui-même: as Cardinaletti and Starke (1999) discuss in detail (see also Zribi-Hertz (2000) for related considerations in French), this type of competition is also found with strong pronouns such as lui (him) (once again without contrastive or deictic accent on it) and their clitic counterpart such as le (him):

(52) a. * Jean examinera lui $_{\mathrm{q}}$ ' $\mathrm{John}_{\mathrm{i}}$ will examine himq.'

b. $\operatorname{Jean}_{\mathrm{i}} \mathrm{l}_{\mathrm{q}}$ 'examinera.

'John ${ }_{\text {i will examine him }}$.'

(53) a. ?? $\mathrm{Jean}_{\mathrm{i}}$ décrit le paysage à lui ${ }_{\mathrm{q}}$.

' $\mathrm{John}_{\mathrm{i}}$ describes the landscape to him $\mathrm{q}$.'

b. Jean $_{\mathrm{i}}$ lui $_{\mathrm{q}}$ décrit le paysage.

'John ${ }_{\mathrm{i}}$ describes the landscape to him $_{\mathrm{q}}$ '

\footnotetext{
${ }^{29}$ Note nevertheless that when se is available, elle-même can also be acceptable if it is added to se; this gives rise to focusing of the reflexivized object (and irrelevantly can also yield an exclusive reading of the subject in (i) like emphatic himself can do):

(i) Jean $\mathrm{S}_{\mathrm{i}}$ ' examinera lui $\mathrm{i}_{\mathrm{i}}$-même/ 'John $\mathrm{i}_{\mathrm{i}}$ will examine HIMSELF $\mathrm{H}_{\mathrm{i}}$ '

(ii) $\mathrm{Jean}_{\mathrm{i}} \mathrm{Se}_{\mathrm{i}}$ décrit le paysage à lui $\mathrm{i}_{\mathrm{i}}$-même / ' $\mathrm{John}_{\mathrm{i}}$ describes the landscape to HIMSELF $\mathrm{F}_{\mathrm{i}}$.
} 
(54) a. Marie $_{\mathrm{i}}$ dépend d'elle $\mathrm{q}^{30}$

'Maryi depends on her ${ }_{\mathrm{q}}$ '

b. * Marie $_{\mathrm{i}}$ lui $\mathrm{i}_{\mathrm{q}}$ dépend.

'Maryi depends on her ${ }_{\mathrm{q}}$ '

(55) a. * Marie a présenté $\operatorname{Jean}_{\mathrm{i}}$ à lui ${ }_{\mathrm{p}}$.

'Mary introduced $\mathrm{John}_{\mathrm{i}}$ to himp.'

b. Marie $_{\mathrm{k}}$ lui $_{\mathrm{p}}$ a présenté Jean $\mathrm{i}_{\mathrm{i}}$.

'Mary introduced John $_{\mathrm{i}}$ to himp.

(56) a. * Jean ${ }_{\mathrm{i}}$ a été assigné à lui .

b. Jean lui $_{\mathrm{p}}$ a été assigné

' $\mathrm{John}_{\mathrm{i}}$ has been assigned to him ${ }_{\mathrm{p}}$ ''

Interestingly, this pattern of competition generalizes to exempt anaphor cases where lui-même has an antecedent in a different clause:

(57)a. * Jean ${ }_{\text {i }}$ pense que Marie examinera lui ${ }_{i}$-même.

' $\mathrm{John}_{\mathrm{i}}$ thinks that Marie will examine himself $\mathrm{i}_{\mathrm{i}}$ '

b. Jean $_{\text {i }}$ pense que Marie $\mathrm{l}_{\mathrm{i}}$ ' examinera.

'John thinks that Marie will examine him $_{\mathrm{i}}$ ',

(58)a. ??Jean ${ }_{i}$ pense que Marie décrit le paysage à lui ${ }_{i}$-même

' $\mathrm{John}_{\mathrm{i}}$ thinks that Marie describes the landscape to himself $\mathrm{f}_{\mathrm{i}}$.'

b. $\operatorname{Jean}_{\mathrm{i}}$ pense que Marie lui $\mathrm{i}_{\mathrm{i}}$ décrit le paysage.

' $J_{o h n}$ thinks that Marie describes the landscape to him ${ }_{\mathrm{i}}$ '

(59)a. Marie ${ }_{i}$ s'inquiète du fait que ses enfants dépendent d'elle ${ }_{i}$-même.

'Mary $\mathrm{y}_{\mathrm{i}}$ is worried that her children depend on herself $\mathrm{f}_{\mathrm{i}}$.'

b. * Marie $_{\mathrm{i}}$ s'inquiète du fait que ses enfants la $\mathrm{a}_{\mathrm{i}}$ dépendent.

'Mary ${ }_{\mathrm{i}}$ is worried that her children depend on her $_{\mathrm{i}}$.'

(60)a. ??Jean ${ }_{\text {i }}$ pense que Marie a présenté Suzanne à lui ${ }_{\mathrm{i}}$-même.

' $\mathrm{John}_{\mathrm{i}}$ thinks that Marie will examine himself $\mathrm{i}_{\mathrm{i}}$ '.

b. Jean ${ }_{i}$ pense que Marie lui $i_{i}$ a présenté Suzanne.

' $\mathrm{John}_{\mathrm{i}}$ thinks that Marie will examine himi ${ }_{\mathrm{i}}$ ''

(61)a.??Jean ${ }_{i}$ pense que Marie a été assignée à luii ${ }_{i}$-même.

' $\mathrm{John}_{\mathrm{i}}$ thinks that Marie has been assigned to himself $\mathrm{i}_{\mathrm{i}}$ '

b. Jean $_{\mathrm{i}}$ pense que Marie lui ${ }_{\mathrm{i}}$ a été assignée.

' $\mathrm{John}_{\mathrm{i}}$ thinks that Marie has been assigned to himself $\mathrm{i}_{\mathrm{i}}$ '

Based on all these examples, it seems that, as argued by Cardinaletti and Starke (1999), an economy principle is at play: if a pronominal clitic is available (reflexive, accusative or dative), it must be used and blocks use of bare elle(-même). ${ }^{31}$

\footnotetext{
${ }^{30}$ Note that the strong pronoun is not in competition with the clitic en (of it/ of her) even though Marie $_{i}$ en $_{q q}$ dépend can be synonymous with (58a).

${ }^{31}$ As expected, this is true even if the antecedent is not a subject, e.g.

(i) ??Marie a informé Jean ${ }_{i}$ qu'on présenterait Suzanne à lui ${ }_{i}$-même/ 'Mary informed John ${ }_{i}$ that one would introduce Susan to himself ${ }_{\mathrm{i}}$,
} 
As expected under their view, all the excluded examples with either elle or elle-même improve if the pronouns are deictic or strongly focused:

(62)(?) Jean ${ }_{i}$ pense que Marie examinera $\mathrm{LUI}_{\mathrm{i}}(-\mathrm{MÊME})$. ' $\mathrm{John}_{\mathrm{i}}$ thinks that Marie will examine HIM(SELF) ${ }_{\mathrm{i}}$.

Given the is conclusion, the answer to question (50b) might seem obviously related to the fact that English lacks the kind of pronominal clitic system French has, coupled with the system of anaphor exemption operative in English. We have not discussed English here but let us note that the similarities between English and French appear much stronger than initially seems once focus and accenting are taken into account. This is discussed in Ahn (2012, forthcoming).

\section{Fine tuning Condition A and Deriving It}

The previous argumentation concludes that the classical condition A is basically the correct generalization (in French) regulating the distribution of plain anaphors. We now turn first to the question of how precisely to formulate Condition A and next how its effects could be derived from more basic theoretical principles.

We will conclude first that Chomsky's (1986) formulation should be amended to disallow a plain anaphor from taking an antecedent outside a tensed TP containing it. Secondly, examining the properties of the antecedent/plain anaphor binding relations, we will conclude that the best strategy to attempt to reduce condition A to more primitive conditions is to reduce it to Phase theory, and we will examine what this entails for Phase theory.

\subsection{Fine tuning Condition A}

Taking into account the plain/exempt distinction, in this section, we only deal with plain anaphors, which we will systematically illustrate with inanimate anaphors.

We can paraphrase Chomsky's 1986 formulation of condition A as "a plain anaphor must be bound within the smallest complete functional complex containing a structural binder for the anaphor".

A complete functional complex is understood to be some phrasal projection only containing saturated predicates (that is predicates with all of their arguments). Given the predicate internal subject hypothesis and trace theory, a complete functional complex for some predicate $\mathrm{p}$ is simply going to be the maximal projection of $\mathrm{p}$. Given furthermore that the binding domain for an anaphor must contain a binder for the anaphor, this formulation is equivalent to requiring that "a plain anaphor must be bound within the smallest XP containing a structural binder for the anaphor”.

It is easy to see that if the anaphor is not the highest, or included in the highest, projected argument of some $\mathrm{X}, \mathrm{XP}$, the maximal projection of $\mathrm{X}$ will be its binding domain.

(ii) ??Marie a informé Jean ${ }_{\mathrm{i}}$ qu’on lui $\mathrm{i}_{\mathrm{i}}$ présenterait Suzanne / 'Mary informed $\mathrm{John}_{\mathrm{i}}$ that one would introduce Susan to him $_{\mathrm{i}}$. 
By definition, the subject of an XP is the highest argument of that XP (if this XP has a subject). It follows that if an XP has a subject which is not or does not contain a plain anaphor, this plain anaphor in XP will have to be bound within this XP. In other words, as we have been assuming so far, and demonstrated to be the case in all instances which we have discussed, a subject cannot intervene between a plain anaphor and its antecedent.

If however the plain anaphor is the highest, or part of the highest, projected argument of some head X, XP, the maximal projection of X will be not be its binding domain, since XP will not, by assumption, contain a binder for the anaphor. In that case the binding domain will be the smallest YP containing XP and a binder for the anaphor.

Putting all together, this comes down to requiring that an anaphor and its antecedent be in the smallest XP containing both without a subject intervening between them.

Illustrating the major cases with English sentences (ignoring exemption here, that's why animates are used) and reflexive anaphors where possible (reciprocals otherwise), here is the major pattern predicted for plain anaphors:

(63)a. $\quad \mathrm{DP}_{\mathrm{k}} \ldots\left[\mathrm{vP} \mathrm{DP}_{\mathrm{m}}\right.$ see herself $\left.\mathrm{m}_{\mathrm{k}} \mathrm{k}\right]$

b. $\quad \mathrm{DP}_{\mathrm{k}} \ldots\left[\mathrm{vp}_{\mathrm{vP}} \mathrm{DP}\right.$ see a picture of herself $\left.\mathrm{m}_{\mathrm{m}, \mathrm{k}}\right]$

c. $\quad \mathrm{DP}_{\mathrm{k}} \ldots\left[\mathrm{DP}_{\mathrm{DP}} \mathrm{DP}_{\mathrm{m}}\right.$ 's picture of herself $\left.\mathrm{m}_{\mathrm{m},{ }_{\mathrm{k}}}\right]$

d. $\quad \mathrm{DP}_{\mathrm{k}} \ldots\left[\mathrm{vp}_{\mathrm{v}} \mathrm{DP} \mathrm{m}_{\mathrm{m}}\right.$ see each other $\mathrm{m}_{\mathrm{m},{ }^{*} \mathrm{k}}$ 's pictures ]

e. $\quad \mathrm{DP}_{\mathrm{k}} \ldots\left[\mathrm{V}_{\mathrm{vP}} \mathrm{DP}_{\mathrm{m}}\right.$ find [AP herself $\mathrm{m}_{\mathrm{m},{ }^{*} \mathrm{k}}$ proud of it ] ]

f. [vp $\mathrm{DP}_{\mathrm{k}}$ find [vp $\mathrm{DP}_{\mathrm{m}}$ proud of herself $\mathrm{m}_{\mathrm{m},{ }_{\mathrm{k}}}$ ] ]

g. [vp $\mathrm{DP}_{\mathrm{k}}$ believe [vp $\mathrm{DP}_{\mathrm{m}}$ to know herself $\mathrm{m}_{\mathrm{m}, \mathrm{k}}$ ] ]

h. $\quad \mathrm{DP}_{\mathrm{k}} \ldots$ [vp DP $\mathrm{DP}_{\mathrm{m}}$ believe [xp herself $\mathrm{m}_{\mathrm{m}, \mathrm{k}}$ to know Bill ] ]

i. $\mathrm{DP}_{\mathrm{k}} \ldots\left[\mathrm{vp}_{\mathrm{DP}}\right.$ believe [vp a picture of herself $\mathrm{m}_{\mathrm{m}, \mathrm{k}}$ to show ... ] ] inside subject of

ECM clause

j. $\quad \mathrm{DP}_{\mathrm{k}} \ldots$ [vp $\mathrm{DP}_{\mathrm{m}}$ believe that [vp herself ${ }_{\mathrm{m},{ }_{\mathrm{k}}}$ knows Bill ] ] subject of tensed clause

k. $\quad \mathrm{DP}_{\mathrm{k}} \ldots\left[\mathrm{vp} \mathrm{DP}_{\mathrm{m}}\right.$ believe that [vp a picture of herself $\mathrm{m}_{\mathrm{m},{ }_{\mathrm{k}}}$ shows ...] ] inside subject

of tensed clause

We have discussed most of the corresponding cases in French with inanimate, that is plain, anaphors. They conform exactly to this pattern with two exceptions: such cases as (67e, h), discussed for elle-même in section 5 and involving (as accusatives) a French specific competition with weak forms; cases like (67j, k) to which we now turn.

In Chomsky’s 1986, (67j, k) with m indices are both predicted fine. Since the first one is actually ill formed, a special mechanism is needed to exclude it. ${ }^{32}$ The second sentence however is fine with the indexing indicated. However we do not know whether this is a case of exempt anaphora or plain anaphora (since these examples involve animates). Constructing comparable examples in French with plain anaphors (inanimates) yields deviant sentences:

(64)a. [Cette auberge $]_{\mathrm{i}}$ bénéficie du fait que $\left[{ }_{\mathrm{TP}} \operatorname{son}_{\mathrm{i}}\left({ }^{*}\right.\right.$ propre) jardin est plus spacieux que celui des auberges voisines].

'[This inn $]_{\mathrm{i}}$ benefits from the fact that ${ }_{\mathrm{TP}} \mathrm{its}_{\mathrm{i}}\left({ }^{*} \mathrm{Own}\right)$ garden is more spacious than that of the neighboring inns].'

b. $\quad$ [Ce musée $]_{\mathrm{i}}$ indique que $\left[_{\mathrm{T} P}\right.$ l'équipe de $\operatorname{son}_{\mathrm{i}}\left({ }^{*}\right.$ propre) conservateur collabore avec

\footnotetext{
${ }^{32}$ In Chomsky (1986), appeal is made to required, but illegal, movement of the anaphor to its antecedent. Rizzi (1990) develops an alternative in terms of his Anaphor-Agreement effect.
} 
d'autres conservateurs de musée].

'[This museum $]_{\mathrm{i}}$ indicates that the team of its ${ }_{\mathrm{i}}{ }^{*}$ own) curator collaborates with other curators.'

c. [La Terre $]_{\mathrm{i}}$ pâtit du fait qu'[тр elle ${ }^{-}\left({ }^{*}\right.$ ême) n'a pas la priorité sur les hommes].

'[The earth $]_{\mathrm{i}}$ suffers from the fact that $\mathrm{it}_{\mathrm{i}}\left({ }^{*}\right.$ self) does not get priority on humans.'

d. * [La Terre $]_{\mathrm{i}}$ a bénéficié du fait que [тр des photos d'elle ${ }_{\mathrm{i}}$-même et de son satellite ont montré les effets néfastes de la pollution].

'[The earth $]_{i}$ benefited from the fact that pictures of itself $f_{i}$ and its satellite showed the harmful effects of pollution.’

In other words, a French plain anaphor in a tensed TP disallows a (closest) antecedent located outside of this TP. This prohibition is not a blanket prohibition against anaphors, as exempt anaphors are of course allowed, as illustrated by the following example with elle-même in subject position:
Au début c'est sa belle-soeur qui va venir prendre ses enfants, puis [тр elle-même viendra]. (google)
'lit. At the beginning, it is her sister-in-law that will pick up her children, then herself will come.'

We conclude that the classical Condition A must be amended as follows:

(66) Condition A: "a plain anaphor and its binder must be the smallest XP containing both without an intervening subject and no larger than a tensed TP”.

The next question is how to derive the effects of this condition: this is what we turn to now.

\subsection{Condition A and Phase Theory.}

Condition A as formulated above imposes a locality requirement on plain anaphor antecedent binding. Proceeding parsimoniously, we should attempt to derive this requirement from existing, independently motivated requirements. Current theories (Chomsky 2001, 2008) contain exactly two hypotheses imposing locality effects:

1. Closest Attract (or Probe-Goal relations)

2. Phase theory

Phase theory (because of the Phase Impenetrability Condition) imposes absolute locality requirements: an element inside the spell out domain of a phase head cannot be syntactically directly related to an element outside of this phase.

By contrast, Closest Attract imposes relative locality requirements. It can only relate elements that are closest to each other and in particular it is sensitive to intervention effects: a probe cannot see a Goal across an intervening Goal (when they are all within a single phase of course).

This difference suggests that we should attempt to reduce Condition A to Phase theory and not to Closest Attract. There are two reasons for this. 
First, antecedent/anaphor binding quite generally does not care about intervening elements. Consider the following well-formed example:

(67) [Cet algorithme $]_{\mathrm{m}}$ construit [chaque image $]_{\mathrm{k}}$ en fonction de [DP\# $\mathrm{Sa}_{\mathrm{m}}$ propre analyse de $\mathrm{sa}_{\mathrm{k}}$ structure ]

This algorithm builds each image as a function of its own analysis of its structure

Here the plain anaphor sa (propre analyse) (its own analysis) is bound by the subject across chaque image (each image) which binds the pronoun sa (structure) (its structure). This pattern could be duplicated with all sorts of quantifiers (e.g. downward entailing). We therefore know that the object chaque image (each image) must c-command DP\#. It thus intervenes between the antecedent cet algorithme (this algorithm) and the plain anaphor sa (propre analyse) (its own analysis) without blocking it.

This point could even be made stronger with the following example, in which the intervener must also be c-commanded by the subject as it contains a plain anaphor bound by it:

(68) [Cet algorithme $]_{\mathrm{m}}$ construit [chaque image de lui-même $\left.\mathrm{m}_{\mathrm{m}}\right]_{\mathrm{k}}$ en fonction de [DP\# $\mathrm{sa}_{\mathrm{m}}$ propre analyse de $\mathrm{sa}_{\mathrm{k}}$ structure ]

This algorithm builds each image of itself as a function of its own analysis of its structure

Secondly, it is well known - historically this is one of the main motivations for the distinction between A and A-bar positions - that anaphors cannot come to be bound because of A-bar movement. Thus, consider the following examples:
a. * These pictures, each other's authors disliked?
b. * Quels tableaux leurs propres reproductions (et non pas celles d'autres tableaux du même artiste) ont-elles dévalués? Which paintings did their own reproductions devalue?
c. * Quels tableaux des reproductions d'eux-mêmes ont-elles dévalués ?
* Which paintings did reproductions of themselves devalue?

Such examples are ill-formed, regardless of the status (plain or exempt) ${ }^{33}$ of the anaphor. The deviance is not due to weak crossover as referential antecedents (see Lasnik and Stowell, 1991) do not trigger, or which-phrases (see e.g. Hornstein, 1995) trigger weaker, crossover effects. Under a Closest Attract approach, this is unexpected as antecedent and anaphor are (in a single phase and) not separated by any intervener.

We take this to mean that the locality requirement must come from Phase Theory. We turn next to how this could be done and what it means for Phase theory.

\subsection{Deriving Binding Locality from Phase Theory}

Descriptively, this is essentially the conclusion that we reached:

$$
\text { Binding domain for (French) plain anaphors }
$$

\footnotetext{
${ }^{33}$ The fact that such examples are excluded is interesting in itself, and would bear on the proper formulation of the theory of what is allowed to count as an antecedent for an exempt anaphor.
} 
A plain anaphor:

- must be bound in its tensed TP

- cannot be separated from its antecedent by a subject.

In order to derive binding locality from Phase Theory, consider standard assumptions of phase theory (Chomsky, 2001, 2008): ${ }^{34}$

- Phase Heads include C, and v.

- Tensed TP is the spellout domain of the $\mathrm{C}$ phase.

- Everything in vP (resp DP) but the subject is the spellout domain of the $v$ phase.

This immediately suggests the central idea we want to pursue: TP is a spellout domain and also an opaque domain for condition A. Quite generally we could take binding domains to be spell out domains. This brings us to the following two proposals to unify binding locality and phase theory:

\section{Proposal \#1}

There is a domain because Condition A:

- applies at the interface

- applies cyclically

(72) Proposal \#2: the binding domain for condition A is the spell out domain of a phase (i.e. what becomes incrementally visible to meaning computation):

Condition A: a plain anaphor must be interpreted within the spellout domain containing it.

The first proposal, essentially taking Condition A to apply at LF cyclically is not new. The LF part has been extensively argued for, e.g. in Fox (2000), Sportiche (2005), which document systematic interdependence between binding properties and scope properties. The cyclic part is implicit in Landau (2007) and explicit in e.g. Lee-Schonfeld (2008), Quicoli (2008). ${ }^{35}$

The second proposal is new and has two ingredients. First crucial reference is made to "spell out” domain and not to Phase. This is crucial in our deriving the fact that tensed TPs boundaries are opaque for condition A. Second, we will construe the appeal to "contain" literally, and this will help us explain why movement can increase the binding possibilities of an anaphor - e.g. it can escape tensed TPs by wh-movement - despite the copy theory of movement: in such cases, a single object is simultaneously present both inside and outside a spell out domain and is thus not contained in that spell out domain.

\subsubsection{The case of TP}

\footnotetext{
${ }^{34}$ As in Chomsky (2008), we simplify the discussion by taking C (and thus the edge of a phase) to possibly stand for several projections in the left periphery along the lines of Rizzi (1997).

${ }^{35}$ We do not take a stand here on the validity of the grounds under which such proposals were put forth as ours are different.
} 
Let us illustrate this with the case of tensed TP (in this subsection, we will write all the examples in English to simplify the presentation but remember that all examples are meant to be French examples with plain anaphors).

In this case we have a finite TP complement of the phase head C. The following two sentences have the structure indicated below:

(73)a. Mary believes that herself knows Bill

b. Mary believes that a picture of herself shows that....

$$
\begin{aligned}
& \text { antecedent }\left[\text { CP SPEC }\left[\mathrm{C}_{\text {phase head }}[\mathrm{TP} \ldots \text { anaphor ... }]\right]\right. \\
& \leftarrow \text { phase } \quad \text { edge } \rightarrow \leftarrow \text { spellout domain } \rightarrow
\end{aligned}
$$

Once the phase is completed, the spell out domain TP is transferred. This domain contains an anaphor. By Condition A as formulated in (76), this anaphor must be interpreted, that is get its referential value within that TP. Since the antecedent is external to TP, this type of representations crashes, ruling out both sentences in (77).

Note how this immediately derives why movement such as wh-movement, or topicalization (both superficially unbounded, hence) to phase edges cannot supply new antecedents for anaphors: if the moved phrase did not qualify as an antecedent (e.g. via c-command) for the anaphor prior to movement, movement to the edge will not supply one as, by assumption this moved phrase will not remain within TP, the spell out domain. This is illustrated below for sentence (73b):

$$
\begin{aligned}
& \text { * Which paintings did reproduction of themselves devalue? } \\
& \text { [CP antecedent }\left[\mathrm{C}_{\text {phase head }} \mathrm{C}_{\mathrm{TP}} \quad \ldots\right. \text { anaphor ... } \\
& \leftarrow \text { phase edge } \rightarrow \leftarrow \text { spellout domain } \rightarrow
\end{aligned}
$$

\subsubsection{The Case of vP and similar XPs with subjects}

The case of vP is somewhat more complicated. Consider the case of a verbal XP embedded say, under a causative verb:

(74)a. $\quad[\mathrm{vP} \text { [La terre }]_{\mathrm{m}}$ laisse [[sa $\mathrm{sa}_{\mathrm{m}}$ propre atmosphère $]_{\mathrm{k}}$ modifier [sa $*_{\mathrm{m}, \mathrm{k}}$ propre composition]]]

$\begin{array}{clc}\text { The earth let } & {[\mathrm{xP} \text { its own atmosphere modify } \underline{\text { its }} \text { own composition ] }} \\ \text { b. } \quad \mathrm{DP}_{\mathrm{m}} & {\left[\mathrm{XP} \frac{\mathrm{DP}}{\mathrm{DP}_{\mathrm{k}} \ldots}\left[\mathrm{DP}_{\mathrm{p}} \ldots\right.\right.}\end{array}$
$\left[\mathrm{XP} \mathrm{DP}_{\mathrm{k}} \ldots\right.$
$\mathrm{X}\left[\mathrm{DP}_{\mathrm{p}} \ldots\right.$

This sentence represents a general pattern (where X can be v, an ECM T, a small clause head, a $\mathrm{D}$, an $\mathrm{N}$, etc..,) in which the subject of $\mathrm{XP}, \mathrm{DP}_{\mathrm{k}}$, can be or can contain an anaphor bound from outside XP, e.g. by $\mathrm{DP}_{\mathrm{m}}$; and an object further embedded, $\mathrm{DP}_{\mathrm{p}}$, can be or can contain an anaphor bound by the subject of $\mathrm{XP}, \mathrm{DP}_{\mathrm{k}}$, but not anything further away, e.g. $\mathrm{DP}_{\mathrm{m}}$.

The sentence in (78a) illustrates this pattern: its own atmosphere can antecede its (own composition): XP must be no bigger than a spell out domain. But we also see that its (own composition) cannot be bound by the earth: given our proposal, there must be a spell out domain containing the former but not the latter. In other words, there must a phase boundary between the subject of XP and the subject of vP. 
However, its (own atmosphere) can be bound by the earth: they must be in the same spell out domain.

We thus reach a contradiction if the structure is as indicated.

This means the structure of (78a) cannot be as shown in (78b). We need to have the subject of $\mathrm{XP}$ both in the same spell out domain as the earth and as its (own composition) but these two DPs cannot be in the same spell out domain.

In fact the standard assumption about such structures is nearly all we need to resolve this apparent contradiction: such structures are "raising-to-object" structures where the embedded subject has raised into the main clause. Thus, a better representation of (78a) is not (78b) but (78c) as follows:

(78)c.

$$
\begin{aligned}
& \mathrm{DP}_{\mathrm{m}} \quad\left[\mathrm{xp}_{\mathrm{XP}} \mathrm{DP}_{\mathrm{k}} \mathrm{X}\left[\begin{array}{lll}
\mathrm{YP}_{\mathrm{HP}} \mathrm{DP}_{\mathrm{k}} & \mathrm{Y} & \mathrm{DP}_{\mathrm{p}}
\end{array}\right]\right. \\
& \leftarrow \text { binding possible } \rightarrow \quad \leftarrow \text { binding possible } \rightarrow \\
& \leftarrow \text { binding impossible } \rightarrow
\end{aligned}
$$

In other words, there are two occurrences of the $\mathrm{DP}_{\mathrm{k}}$ its own atmosphere: one inside the projection YP, which is the trace of the one raised outside of YP. To handle the binding possibilities in a way that is consistent with our construal of Condition A, it suffices to take YP to be (part of) the spellout domain, and $\mathrm{DP}_{\mathrm{k}}$ to have moved out of it to the edge of some phase head, say $\mathrm{X}$ here for concreteness. ${ }^{36}$

This predicts that:

$\mathrm{DP}_{\mathrm{p}}$ (or something it contains) has a possible antecedent within its spellout domain YP, namely the trace $\mathrm{DP}_{\mathrm{k}}$. But $\mathrm{DP} \mathrm{m}_{\mathrm{m}}$ is outside of this spell out domain and thus cannot antecede $\mathrm{DP}_{\mathrm{p}}$.

$\mathrm{DP}_{\mathrm{k}}$ is actually not contained in YP (although one occurrence of it is): indeed we are dealing with a single object with two occurrences, ${ }^{37}$ one inside YP, the other not. Not being contained within YP, it is not subject to condition A within YP and it (or an anaphor it contains) can thus be bound by $\mathrm{DP}_{\mathrm{p}}$.

This way of construing containment (as a property of objects and not of occurrences) is in fact independently motivated. For example, wh-moving say, the container of a plain anaphor increases its binding options. This has long been assumed, e.g. for such examples as:

\section{(75) They know [ which pictures of themselves [ I like which pictures of themselves ] ]}

Such sentences are well formed even though the lower copy of the anaphor does not satisfy Condition A: what matters is the highest copy. ${ }^{38}$ We can demonstrate the same effect in French, controlling at the same time for the plain status of the anaphor involved (something that should be done for English too):

(76) La terre soulève la question de quel effet sur sa propre inclinaison (et sur

\footnotetext{
${ }^{36} \mathrm{DP}_{\mathrm{k}}$ could also have moved past the edge, which would not change the essence of what we present. For simplicity's sake, we will ignore this option here.

${ }^{37}$ It is necessary (under the copy theory of movement) to distinguish the case of remerge/move of some item from the superficially similar case of two objects being identical in all respects including their index and merged independently. The former is the case of Move, subject to Phase locality, the latter is not. Thus the notion of "single object with multiple occurrences" is needed.

${ }^{38}$ More precisely, the highest non reconstructed copy, an issue we cannot really explore here, but see Sportiche, 2003, 2005. Additional motivations for construing containment as a property of objects are found in Sportiche, 2011, 2012.
} 
celle de la lune) le vent solaire a eu quel effet sur sa propre inclinaison . 'The earth raises the question of what effect on its own obliquity and the moon's ) the solar wind has had t'

Here the wh-moved phrase allows the inanimate possessor son propre to take as antecedent the main clause subject, a relationship that would not be allowed without movement. ${ }^{39}$

The consequences of this discussion are several.

First, extending the logic of the TP case to this (and other cases) adds a source of evidence regarding the inventory of Phase heads. The usual one is based on Movement/Agree, that is on Closest Attract/ Probe Goal configurations that fail in the absence of any intervention, revealing the presence of a (absolute) Phase boundary. This new source of evidence would be based on the binding possibilities for plain anaphors: if a c-commanding antecedent/plain anaphor (local) binding relation is well formed, there can't be a phase boundary between them and if it is ill formed (even though all conditions are met except locality) there must be.

Secondly, the above conclusions require a slight rethinking of the vP edge as the subject of vP needs to start inside the $\mathrm{vP}$ spell out domain and move out of it. The reason why the $\mathrm{vP}$ subject is usually considered to be merged at the edge is not completely clear to us, but an equivalent outcome would arise (with all the same advantages and drawbacks) if there is a phase head above vP attracting (probing) DPs: it would have to attract the closest DP first, that is the subject.

More generally this would apply to any XP with a subject, which unlike in the tensed TP case, tolerates being or containing a plain anaphor bound from the outside: vP, ECM infinitive, small clauses (both of which would involve "raising to subject”), ${ }^{40}$ DP's which would all to involve a phase head (as has been argued in the case of DPs in Svenonius, 2003). In all cases, there would have to be movement of the subject from a spell out domain internal position to the edge of the immediate superordinate phase head associated with this spell out domain.

Summarizing the discussion of XPs observed with subject, we reasoned that if

(i) XP's subject is bindable from outside, it is outside the spellout domain (at phase edge)

(ii) XP's subject can bind an anaphor within XP, it starts inside the spellout domain

And we concluded:

the subject of XP is both inside the spell out domain and at the edge: if XP has a subject, XP must be (included in) a phase and the subject has raised to its edge from some lower position inside the spell out domain of this phase head. This is graphically represent below:

\footnotetext{
${ }^{39}$ The property of movement to the edge to extend the binding of anaphors could perhaps be exploited to explain why, in languages like Chinese, anaphors in subject position can take antecedent outside of their clauses even when they are plain (as shown in Huang and Liu, 2001): if such subjects had moved into the edge, this would be expected. Fn 34 may be relevant.

${ }^{40}$ Evidence for this can be readily found with floated quantifiers assuming Sportiche 1988 or 1997's analysis, viz: (i) Elle trouve [ [les enfants] $]_{\mathrm{k}}$ [ tous $\mathrm{t}_{\mathrm{k}}$ beaux ] ]/ She finds the children all handsome, (ii) Elle a vu [ [les enfants $]_{\mathrm{k}}$ [ tous $\mathrm{t}_{\mathrm{k}}$ rire ] ]/ she saw the children all laugh.
} 


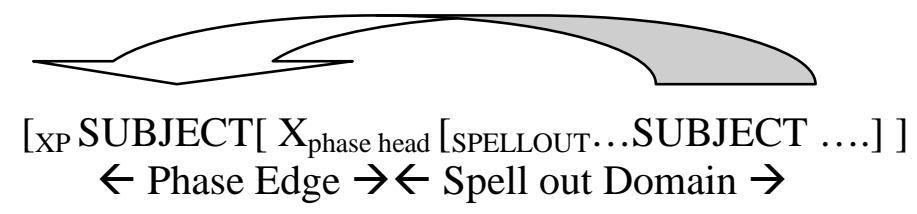

\subsubsection{The Case of XPs without subjects}

Let us now turn to the cases of XPs lacking subjects. Empirically, what we have observed is that in such cases (VP, DP, NP), binding of a plain anaphor is allowed into XP from outside XP. English examples illustrating this possibility could be:

(77)a. Mary saw [DP a picture of herself ]

b. Mary ${ }_{k} T$ [vp seem to herself $f_{k}$ [ $t_{k}$ to be a good candidate ]

Such examples as they stand are of course not telling as we need to make sure that herself is not exempt. Here are some close equivalent in French where we control for non exemption (with inanimates):

(78) a. [La terre $]_{\mathrm{m}}$ souffre [DP du réchauffement [DP de sa $\mathrm{m}_{\mathrm{m}}$ propre surface et de celle de la lune]] The earth suffers from the heating of its own surface (and of that of the moon).

b. [L'horloge $]_{\mathrm{m}}$ a [vp semblé ralentir à son $\mathrm{m}_{\mathrm{m}}$ propre fabricant et au fabricant de celle-là] ${ }^{41}$ The clock seemed to slow down to its own maker and to the maker of that one.

From this we must conclude that neither the DPs, nor the VP headed by seem can be spell out domains. Otherwise, the plain anaphor and the (derived) subjects would not belong to the same spell out domains and binding would be excluded. Once again, this type of assumption is standard: (some) control infinitives are assumed to be phases (as they exclude movement out of them probed by a higher $\mathrm{T}$ : they are introduced by a $\mathrm{C}$ phase which turns the infinitive TP into a spell out domain). Raising infinitives on the other hand are not phases for a symmetrical reason: the embedded subject can be probed by a higher $\mathrm{T}$ so no phase boundary can intervene.

In order to explain what happens with DP's, we need to assume that a DP must be a phase only if it licenses a genitive subject, otherwise it is not. Thus the phase inducing head must be that responsible for prenominal pronouns (in French; and, presumably, prenominal genitives in English). ${ }^{42}$

Similarly, in the case of the sembler/seem headed VP: it can't be a Phase (as is standardly assumed given that the main $\mathrm{T}$ can probe into the infinitive) since the experiencer can come to be bound by the raised subject.

\subsubsection{Binding Locality from Phases: Predictions for Extraction}

Note first that different phases show different extraction possibilities.

Unlike the CP edge, the VP edge is tolerant: while the CP edge in languages like French (or English) only tolerates one (wh-)element (giving rise to some islands), the vP edge under the

\footnotetext{
${ }^{41}$ Unlike English, French requires extraposition of the experiencer in raising cases. This sentence must thus be read with the appropriate intonation.

${ }^{42}$ This may be tied to when possessor raising is allowed/required: precisely when a possessor lacks DP internal Case licensing and can thus escape the non phasal DP.
} 
standard view tolerates multiple elements (the subject, possibly an object, a wh-phrase - on its way to the $\mathrm{C}$ edge).

A French DP on the other hand is intolerant: just like CP, only one element can be attracted to the edge, if there is a phase head licensing a prenominal genitive. Given our reasoning above, this attracted element must be the subject of the DP if there is one. Once again, such an assumption is independently justified. Indeed, as is well known for French (see e.g. Sportiche, 1990, Valois, 1991), wh-extraction from inside DP is possible, but only if the extracted phrase can independently become the subject of the DP: this falls out if the edge of the DP phase is intolerant, like the CP phase, only allowing one element, which must be the subject of DP. We end up with the following picture: extraction from inside XP is possible or not depending on how tolerant of multiple elements the edge is.

Tolerant phases: Multiple Extraction possible. Ex: vP, ECM infinitives, small clauses Intolerant phases: Multiple Extraction impossible. Ex: CPs, DPs

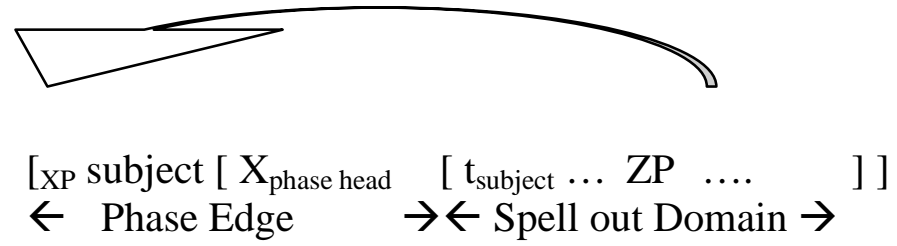

We are claiming that the presence of the subject of an XP typically reveals the presence of a Phase boundary because of binding reasons. This establishes a connection between binding theory and movement theory in the following way: if a subject reveals the presence of a phase boundary, we should expect to see island effects due to the presence of this phase boundary correlating with the presence of a subject. But we should only expect to see evidence of such effects in intolerant Phases, that is DPs or CPs (as tolerant phases allow multiple extraction anyway) and for constituents showing phase variability. Basically, this means DPs which may or may not be phases, as opposed to CP's which always are phases.

In other words, we should expect to find cases in which

0 A given DP without subject tolerates extraction (it is not a phase)

o The apparently same DP with a subject precludes extraction (it is a phase and extraction is blocked)

Such effects are indeed observed in French and illustrated by the following cases of encliticization: 

a. Pierre examine [DP la/une photo de cet immeuble] 'Peter examine the/a picture of this building.'
b. Pierre en examine [Dp la/une photo en ]
Peter en examine the/a picture en
'Pierre is examining the/a picture of it.'
c. Pierre examine [DP ma photo de cet immeuble]
'Peter examine my picture of this building.'
d. * Pierre en examine [DP ma photo en ]
Peter en examine my picture en
'Pierre is examining my picture of it.'

This first paradigm (83a-d) shows that extraction of en, the genitive clitic DP complement of the head noun is sensitive to the presence of the possessive subject: a subject (here ma (my)) blocks extraction (the same pattern holds if the extracted DP was a wh-phrase).

What is crucial is that even in cases where a DP c-commands a genitive en, movement is not blocked (so that a violation of Closest Attract is unlikely). This is shown, e.g. by the following case in which the Small Clause SC is also a phase, but a tolerant one:
a. Pierre
croit [sc Jean [ capable de ça] ]
'Peter
believes
Jean capable of it.'
b. Pierre
en croit
[sc Jean [ capable en ] ]

In such a case, the intervening subject Jean does not block the movement of en, an unexpected outcome if an intervening DP blocked probing.

Furthermore, blocking of en-extraction by a DP subject of DP occurs (even if en is not plausibly analyzed as a moving DP, thus not plausibly probed by the same element as this subject).

$$
\begin{aligned}
& \text { a. Pierre lit [DP trois livres (de cuisine)] } \\
& \text { 'Peter read three books (about cooking).' } \\
& \text { b. Pierre en lit [DP trois en ] (, de livres de cuisine) } \\
& \text { Peter en read three en (,of books about cooking) } \\
& \text { '(As for (cook) books,) Pierre read three.' } \\
& \text { c. * Pierre en lit [DP mes trois en ] (, de livres (de cuisine)) } \\
& \text { Peter en read my three (, of books(about cooking)) } \\
& \text { '(As for (cook)books,) Pierre read my three.' } \\
& \text { d. Pierre en lit [DP les trois premiers en ] (, de livres) } \\
& \text { Peter en read the three first (, of books) } \\
& \text { '(As for books,) Pierre read the first three.' } \\
& \text { e. * Pierre en lit [DP mes trois premiers en ] (, de livres) } \\
& \text { Peter en read my three first, (, of books) } \\
& \text { '(As for books,) Pierre read my first three.' }
\end{aligned}
$$

A comparison of (83a) and (83b) illustrates that much like one-replacement in English (this big book about cooking/ this big one about cooking/ this big one about cooking / this big one about cooking) the clitic en can replace a bare noun or a bare noun and some or all of its dependents but not numerals. It can thus be analyzed as a pro-NP, moving from DP internal position to clitic position in the T domain. Note in particular that such pro-NP can never be realized as the possessor of a DP. 
What (83c), (83d), (83e) paradigm shows is that the presence of an intervening DP subject blocks extraction of this NP. Because pronominal possessors and definite articles are conflated in French, the interpretation of (83c) is unclear. However (83d) (with definite article but without possessor, extraction possible) and (83e) (identical to (83d), but with possessor, extraction blocked) show that the blocker is not the definite article but is related to the presence of the possessor.

This blocking effect once again is not plausibly an intervention effect on probing as the DP subject and the NP are not attracted by the same elements. If however, the presence of a possessor is made possible by a phase inducing head, all these blocking effects are just reflexes of the intolerant character of this DP phase.

\subsection{Summary}

We have proposed to derive the locality imposed on the relation between a plain anaphor and its local binder by construing condition $\mathrm{A}$ as requiring that the interpretation of an anaphor contained in a spell out domain be computed within that spell out domain.

This has led to slight modifications of Phase theory (regarding both Phase inventory and Edge properties), most independently justified. This has allowed us to account, e.g. in the case of extraction from DPs, for phenomena seemingly showing a mixed behavior: an intervening DP subject selectively blocking extraction of a DP or of a non DP XP.

This has also allowed us to derive two properties of the interaction between movement and binding. First, we have derived why movement to the edge of a potential antecedent never provides new binders for plain anaphors, while predicting that movement to the edge of a plain anaphor does increase the set of potential antecedents for this anaphor.

\subsection{Some Consequences and Questions}

\subsubsection{Reconstruction}

Reuland (2011), in the contexts of the theory of exempt anaphora that it defends, claims (p.93) that there is no need for reconstruction, a least as far as anaphor binding is concerned. Thus, in an example such as (Reuland, 2011, p. 93, ex 26):

(82)a. Which picture of himself/herself does Max think that Lucie likes?

b. Max knows which pictures of himself/herself Lucie likes.

Because the anaphors are all claimed to be in exempt positions, there is no need to assume that any particular structural relation needs to hold between them and their antecedents. Given the theory developed here however, this conclusion does not hold. Indeed, the anaphors' positions are not exempt but they are all animate. To decide whether reconstruction is needed we would need to decide whether these anaphors are exempt in such cases. This would require a theory of when exemption is allowed, that is precisely what conditions an antecedent must meet to make the anaphor it binds exempt.

But there is another way to decide the issue: it suffices to look at what happens with inanimate anaphors in French which we have shown cannot be exempt.

To see this, consider the following pairs of examples involving possessor son propre and ellemême which must be anaphoric with inanimate antecedents: 
(83) a. Cette loi a entraîné la publication d'un livre entier sur ses propres conséquences et celles des décrets associés.

This law led to the publication of a whole book about its own consequences and the consequences of the related decrees

b. Je me demande de quel livre sur ses propres conséquences et celles des décrets associés cette loi a entraîné la publication

I wonder which book about its own consequences and the consequences of the related decrees this law led to the publication of

(84)a. La terre impose des forces latérales sur elle-même du fait de sa rotation

The earth imposes lateral forces on itself because of its rotation

b. Quel genre de forces sur elle-même la terre impose-elle du fait de sa rotation ?

What kind of forces on itself does the earth impose because of its rotation?

In both cases, possessor son propre (resp. elle-même) must be a plain anaphor. Since the second example is well formed, this anaphor should be c-commanded by its antecedent but it is not. However, this structural requirement is met prior to the movement of the wh-phrase. In other words, reconstruction (via the copy theory of movement) must be hypothesized to feed Condition A.

\subsubsection{A/A-bar Distinction}

As we have discussed, certain kinds of movement can feed condition A by providing a c-commanding antecedent not available otherwise. Classically, the difference between movement instances that can feed condition A in this manner and movement that can't was expressed in terms of the A/A-bar position difference. Anaphors were required to be A-bound so that only A-movement could be such a feeder. Even though this amounted to an undesirable stipulation (why is this difference relevant?), it was at least possible to define the A/A-bar difference in a non ad hoc way, namely by taking A-position to be potential theta positions. Indeed, the major motivation for defining A-position in terms of potential theta position was the fact that subjects of TP could be anaphor binders even though they were not always theta positions, e.g. in the following type of raising to subject sentences:

(85)a. Mary $\mathrm{T}$ [vp seem to herself $\mathrm{f}_{\mathrm{i}}$ [ $\mathrm{t}_{\mathrm{i}}$ to be a good candidate]].

Because of the exempt anaphora confound (the reflexive is animate, hence possibly exempt), we repeat here the French example (82b) with an inanimate anaphor to illustrate this point without this confound:

(82)b. [L’horloge $]_{\mathrm{m}}$ a [vp semblé ralentir à son $\mathrm{m}_{\mathrm{m}}$ propre fabricant et au fabricant de celle-là] The clock seemed to slow down to its own maker and to the maker of that one.

However, this type of definition has been rendered unavailable since the introduction of the Predicate Internal Subject Hypothesis which uniformly makes the subject of TPs, or the relevant position from which son propre is bound, never a theta position.

The proposal we are making in effect redefines the A/A-bar distinction not in terms of differences between landing positions, but in terms of movement span (at least as far as Binding theory is concerned) in the following way: 
- A-bar movement is movement to the edge of a phase

- A-movement is movement within the spell out domain of a phase head.

The A/A-bar distinction is historically not invoked solely for its role in feeding binding. It has been claimed to play a role in several other questions such as (i) Is improper movement (A-bar movement followed by A-movement of the same element) allowed? (ii) Weak crossover (A-movement does not trigger weak crossover effects, A-bar movement can) (iii) Licensing of parasitic gaps (A-movement does not license parasitic gaps, A-bar movement can).

All such correlations are controversial but would be worth exploring in the context of our characterization of the A/A-bar distinction.

\subsubsection{Exempt Anaphora and Animacy}

Column 3 of table (40) draws a sharp distinction between animate and inanimate anaphors. This of course should be read with the qualification "as far as condition A is concerned". In other words, while being animate is a necessary condition for exemption, it may not be a sufficient condition. Other requirements on what can qualify as an antecedent may exclude exempt anaphora in cases in which it is otherwise allowed by condition A. The extensive literature on exempt anaphora does make claims about the relevant properties antecedent must have, which we cited in section 1, e.g. logocentricity, perspective, etc... In principle it should be possible to construct cases in which no potential antecedent meets these properties: in such cases, exemption should be disallowed and, if animates are subject to Condition A, we should observe the effects of Condition A with these animate anaphors.

\section{Conclusion}

The goal of this article was to investigate the behavior of anaphors based on French data involving son propre and elle-même with the aim to circumscribe the empirical generalizations subsumed under Condition A of the binding theory, and ultimately to derive its effects. Unsurprisingly, French anaphors clearly support the need to distinguish between plain anaphors that obey condition A and anaphors that are exempt from it: the system handling plain anaphors must be complemented by a theory of exemption.

Because, as suggested by crosslinguistic work, exempt anaphors seem to need to refer to live persons, restricting attention to inanimate anaphors should be a useful tool for circumscribing the scope of Condition A. It turned out this way in French: based on this independent criterion, we have demonstrated that exempt anaphora (i) correlates with inclusive binding possibilities, and (ii) plain anaphors must be bound within a local domain that roughly corresponds to the smallest XP with an intervening subject containing the anaphor no larger than a tensed TP.

We have argued that this view of binding domains can be reduced to phase theory: by formulating condition A as requiring that a plain anaphor must be interpreted within the spellout domain of a phase containing it. This has allowed to derive various properties of anaphor binding, e.g. when movement can feed or bleed condition A, as well as providing new empirical grounding for the notion of Phase, the inventory of phase heads and the paths of syntactic derivations. 
Many questions remain which we cannot address here.

Some are of a general nature.

One concerns the nature of the binding relation between an antecedent and an anaphor which Rooryck and van de Wijngaerd (2012) for example propose to reduce to an Agree relation. Another one evoked earlier asks what makes an expression anaphoric, and beyond this how the behavior of plain and exempt anaphors which can be intrinsically identical, can superficially differ rather radically in terms e.g. of locality.

Some are tied to our particular proposals.

Why should condition A be formulated this way: if our construal of condition A is correct, why must the meaning of plain anaphors be computed in a spell out domain.

(French) inanimate anaphors are never exempt from condition A: are animates always exempt?

How do our findings about French generalize to other languages? While our conclusions are consistent with some findings, e.g. what Huang and Liu (2001) report of the Chinese anaphoric system (as their conclusions entail that PB theories are inappropriate to handle the behavior of plain anaphors such as ta-ziji (himself) in that language, or long distance anaphors such as ziji (self)), it remains to be seen how generally they hold and in particular how they can be integrated with the very substantial body of work on anaphora such as Safir (2004a, 2004b), Reuland (2011) or Rooryck and van den Wyngaerd (2011) in some coherent whole.

Settling these questions must be left to further research.

\section{$\underline{\text { References }}$}

Ahn, Byron. 2012: "External Argument Focus and Reflexive Syntax". Coyote Papers: Working Papers in Linguistics

Ahn, Byron. Forthcoming: Giving reflexivity a voice: Twin reflexives in English. Doctoral Dissertation, UCLA.

Anand, Pranav, 2006: De De Se. Ph.D. Dissertation. MIT.

Ariel, Mira, 1990: Accessing noun-phrase antecedents. London: Routledge.

Büring, Daniel, 2005: Binding Theory. Cambridge Textbooks in Linguistics, CUP.

- 2006: "Focus Projection and Default Prominence". Valéria Molnár \& Susanne Winkler (eds.), The Architecture of Focus. Berlin/New York: Mouton de Gruyter.

- 2008: "What's New (and What's Given) in the Theory of Focus? ". Proceedings of $B L S$.

Cardinaletti, Anna and Michal Starke, 1999. The typology of structural deficiency: A case study of the three classes of pronouns. In Clitics in the languages of Europe, van Riemsdijk H., ed. Berlin - New York: Mouton de Gruyter, 145-233.

Charnavel, Isabelle, 2011: "On French Possessive son propre ('his own'): Evidence for an Interaction between Intensification and Binding". O. Bonami \& P. Cabredo Hofherr (eds.), Empirical Issues in Syntax and Semantics 8, 53-74.

- 2012: On her own: Probing Syntax and Semantics with French propre, Doctoral Dissertation, UCLA.

Chomsky, Noam, 1986: Knowledge of Language: Its Nature, Origin, and Use. New York, Praeger.

_ 2001: "Derivation by phase". Michael Kenstowicz (ed.), Ken Hale: A Life in Language, 1-52. Cambridge, MA: The MIT Press. 
2008: "On Phases". In Freidin, Robert; Otero, Carlos P.; Zubizarreta, Maria Luisa. Foundational Issues in Linguistic Theory. Essays in Honor of Jean-Roger Vergnaud. Cambridge, MA: The MIT Press. pp. 133-166

Den Dikken, Marcel, Liptak, A. and Zsofia Zvolenszky, 2001: "On Inclusive Reference Anaphora: New Perspectives from Hungarian". SCCFL 20 Proceedings.

Everaert, Martin, 1986: The Syntax of Reflexivization. Dordrecht: Foris.

Fox, Danny, 2000: Economy and Semantic Interpretation. MIT Press.

Grodzinsky, Yosef, and Tanya Reinhart, 1993: The innateness of binding and coreference. Linguistic Inquiry 24, 69-101.

Heim, Irene, 1984: "A Note on Negative Polarity and Downward Entailingness". C. Jones and P. Sells (eds.), Proceedings of NELS 14. Department of Linguistics, University of Massachusetts at Amherst.

- $\quad$ 1998: "Anaphora and Semantic Interpretation: a Reinterpretation of Reinhart's Approach". U. Sauerland and O. Percus (eds), The Interpretive Tract. MIT working papers in Linguistics. Written and distributed as a technical report at the University of Tübingen in 1992.

Hestvik, Arild, 1995: Reflexives and Ellipsis, Natural Language Semantics, Volume 3, Issue 2, pp 211-237.

Hornstein, Norbert, 1995: Logical form: from GB to minimalism, Blackwell, Oxford.

Huang, C.-T. James, and C.-S. Luther Liu, 2001: "Logophoricity, Attitudes and ziji at the Interface". Peter Cole et al. (eds.), Long Distance Reflexives, Syntax and Semantics 33, 141-195. Academic Press, New York, 2001.

Kayne, Richard S., 1975: French Syntax: The Transformational Cycle. Cambridge: MIT Press.

- 1994: The Antisymmetry of Syntax (Linguistic Inquiry Monograph 25). MIT Press.

- 2000: "Person Morphemes and Reflexives in Italian, French, and related languages". Parameters and Universals, 131-162. Oxford/New York, Oxford University Press.

Keenan, Edward L., 1988: "Complex Anaphors and Bind a". Lynn MacLeod, Gary Larson, and Diane Brentari (eds), Papers from the 24th Regional Meeting of the Chicago Linguistic Society, 216-232. University of Chicago: Chicago Linguistic Society.

- 2000: An Historical Explanation of Some Binding Theoretic Facts in English. Ms. UCLA.

- 2001: Explaining the Creation of Reflexive Pronouns in English. Ms. UCLA.

Kehler, Andrew, 2002: Coherence, Reference, and the Theory of Grammar. CSLI Publications.

- 2005. "Coherence-Driven Constraints on the Placement of Accent". Proceedings of the 15th Conference on Semantics and Linguistic Theory (SALT-15).

König, Ekkehard and Peter Siemund, 2005: "Intensifiers and Reflexives". M. Haspelmath, M. Dryer, D. Gil \& B. Comrie (eds.), The World Atlas of Language Structures, 194-197. Oxford University Press, Oxford.

Kuno, Susumo, 2004: Empathy and Direct Discourse Perspective. The Handbook of pragmatics. Laurence R. Horn \& G. Ward (eds). Oxford: Blackwell.

Lasnik, Howard, 1989: Essays on anaphora. Dordrecht: Reidel.

Lasnik, Howard and Stowell, Timothy, 1991: "Weakest Crossover," Linguistic Inquiry, 22.4, 687-720.

Oshima, David Y., 2006: Perspectives in Reported Discourse. PhD Dissertation. Stanford University.

Pollard, Carl, 2005: "Remarks on Binding theory". S. Müller (ed.), Proceedings of the HPSG05 Conference. The Ohio State University, CSLI Publications. 
Pollard, Carl and Ivan A. Sag, 1992: "Anaphors and the Scope of Binding Theory", Linguistic Inquiry 23, 261-303.

Reinhart, Tanya and Eric Reuland, 1993: "Reflexivity". Linguistic Inquiry 24.4, 657-720.

Reuland, Eric J., 2011: Anaphora and Language Design (LI Monograph). Cambridge, Mass: MIT Press.

Rizzi, Luigi, 1990: On the anaphor-agreement effect. Rivista di Linguistica 2:27-42.

- $\quad$ 1997: "The Fine Structure of the Left Periphery". L. Haegeman (ed.), Elements of Grammar, Kluwer, Dordrecht.

Roelofsen, Floris, 2010: Condition B effects in two simple steps. Natural Language Semantics 18:115-140.

Rooryck, Johan, and Guido van den Wyngaerd. 2011. Dissolving Binding Theory. Oxford University Press. Oxford, England.

Runner, Jeffrey T. and Elsi Kaiser, 2005: "Binding in Picture Noun Phrases: Implications for Binding Theory". Stefan Müller (ed), Proceedings of the HPSG05 Conference. CSLI Publications.

Safir, Ken, 1996: "Semantic Atoms of Anaphora". Natural Language and Linguistic Theory 14, 545-589.

Safir, Kenneth. 2004a: The Syntax of Anaphora. Oxford: Oxford University Press.

Safir, Kenneth. 2004b: The Syntax of (In)dependence. Cambridge, MA: MIT Press.

Schlenker, Philippe, 2003: "Indexicality, Logophoricity, and Plural Pronouns". Research on Afroasiatic grammar; J. Lecarme (ed). 409-428. Amsterdam: J. Benjamins.

Sells, Peter, 1987: "Aspects of logophoricity," Linguistic Inquiry 18: 445-79.

Sportiche, Dominique, 1988: "A Theory of Floating Quantifiers and its Corollaries for Constituent Structure", Linguistic Inquiry 19.3.

Sportiche, Dominique, 1990: "Movement, Agreement and Case", in Dominique Sportiche, 1998, Partitions and Atoms of Clause Structure, Routledge, London

Sportiche, Dominique, 1997: "Subject Clitics in French and Romance, Complex Inversion and Clitic Doubling”, in Studies in Comparative Syntax, Kyle Johnson and Ian Roberts, eds., Kluwer, Dordrecht, The Netherlands p.189-223

Sportiche, Dominique, 2005: "Division of Labor between Merge and Move: Strict Locality of Selection and Apparent Reconstruction Paradoxes". Proceedings of the Workshop Divisions of Linguistic Labor, The La Bretesche Workshop

- 2011: The vanRiemsdijk/Williams Paradox: in the footsteps of Z. de Fourier, invited presentation the Parallel Parallel Domains Parallel Domains Workshop in honor of Jean Roger Vergnaud, USC.

- 2012: Lean Structure Building; Relative Clauses : more often but only one wayInvited presentation, GIST 5, Ghent.

- $\quad$ in press: "French Reflexive se: Binding and Merge Locality". E. Aboh et al. (eds), Celebrating Locality. Oxford University Press.

Valois, Daniel, 1991: The Internal Syntax of DP, Doctoral Dissertation, UCLA.

Zribi-Hertz, Anne, 1989: "Anaphor Binding and Narrative Point of View: English Reflexive Pronouns in Sentence and Discourse". Language 56, 695-727.

- $\quad$ 1995: "Emphatic or Reflexive? On the Endophoric Character of French lui-même and Similar Complex Pronouns". Journal of Linguistics 31, 331-374.

- 2000: "Les pronoms forts du français sont-ils [+animés] ? Spécification morphologique et spécification sémantique". M. Coene, W. De Mulder, P. Dendale \& Y. d'Hulst (eds). Traiani Augusti vestigia pressa sequamur. Studia linguistica in honorem Liliane Tasmowski. Milan: Unipress. 663-680. 